\title{
A reappraisal of luck versus skill in the cross-section of mutual fund returns
}

\author{
Rong Huang* $\quad$ Dimitrios Asteriou ${ }^{\dagger} \quad$ William Pouliot ${ }^{\ddagger}$
}

\begin{abstract}
The first contribution we make to research on measuring U.S. mutual fund performance is to show that the cross-section bootstrap procedure used in one prominent publication on this topic can easily accommodate conditional asset pricing models. Using this result, we reestimate US fund performance using the conditional asset pricing model of Ferson and Schadt (1996) for the period of time covering January 1984 to September 2006, the same period of time used in this prominent publication. Unlike most of the current research on the performance of U.S. mutual funds, including the latter research, the estimates of fund performance produced here suggest that some funds, on a net return basis, performed very well over this period. Our second contribution is to update the U.S. mutual fund data to the end of 2018 and then to re-estimate fund performance over this longer period of time. These results show that fund performance, on a net return basis, is poor, confirming the findings of previous research that used data ending before 2018. The third contribution is to provide a detailed guide on how the mutual fund data widely used in this literature is constructed. Until now much of the information required to do this has not been made widely available. Our last contribution is to make some policy recommendations that should better align fund manager incentives with the interests of investors, an alignment which current practices have hindered.
\end{abstract}

Keywords: Mutual Funds, Capital Asset Pricing Model; Bootstrap.

Classification: C3, C4, G1.

\section{Introduction}

Research undertaken here is motivated by the paper of Fama and French (2010) (hereafter F\&F) which is a recent contribution to a long running debate on the performance on actively managed U.S. mutual funds. Our interest in their research is to revisit a thorny problem raised in their paper but one they leave to future research. In particular, F\&F state that "capturing time variation in the regression slopes [of equilibrium asset pricing models] poses thorny problems" I]. The problems they face are two fold. One stems from the way they construct their mutual fund data: monthly fund returns do not follow sequentially through time as some months may be missing. Their second problem lies with their simulation procedure, a procedure which randomly samples months. Using this sampling method, they claim, causes them to lose any effects of variation through time in the regression slopes of equilibrium asset pricing models they estimate $^{\square}$. This creates a further problem for them, one that negatively affects their estimates of these slopes and intercepts, but one they make no mention of. If parameters of these asset pricing models are

\footnotetext{
*Nottingham University Business School, University of Nottingham, Jubilee Campus, UK. Email: rong.huang@nottingham.ac.uk

${ }^{\dagger}$ Oxford Brookes Business School, Oxford Brookes University, Oxford, UK E-mail: dasteriou@brookes.ac.uk

¥Birmingham Business School, University of Birmingham, Birmingham, UK. E-mail: w.pouliot@bham.ac.uk

${ }^{1}$ Fama and French (2010) page 1925.

${ }^{2}$ Ibid page 1925 .
} 
assumed constant when, in fact, they vary due to a fund manager's use of publicly available information, parameter estimates will be unreliable and estimated abnormal returns will be biased downwards ${ }^{\text {B }}$.

Their second problem, regarding random sampling of monthly returns, is more difficult to solve but we show their bootstrap procedure easily accommodates a changing market-risk coefficient. More formal discussion of our solutions to their problems appear in later sections of this paper. Anticipating some of the results that come later on, our estimations and simulations show that the negative results reported by F\&F regarding the performance of actively managed U.S. mutual funds, for the period 1984 to September 2006, no longer holds when a more general equilibrium asset pricing model is used to estimate fund performance, a result which supports the conclusions of Huang et al. (2019). The latter authors also find a small percentage of U.S. mutual funds produce positive alpha using returns data that ends March 2015, data that is somewhat dated compared to data used here which is up-to-date to December 2018.

Our second contribution is to provide researchers with a detailed description of how F\&F build their mutual fund database. Because they provide little formal discussion on construction of their dataset, it required a search of recently published articles on this topic. Papers included in that search were F\&F, French (2008), Barras et al. (2010), Evans (2010) and Kosowski et al. (2006). Information provided there allowed us to reconstruct the mutual fund data used by $F \& F$; the appendix of this paper provides a step-by-step guide. Our third contribution is to update the results of F\&F to December 2018 which should provide valuable information for academics and researchers, and to those who use their mutual funds to save for retirement as well as their children's education. Our fourth and last contribution is to make some policy recommendations that should better align fund manager incentives with the interests of investors, an alignment which current practices have hindered.

The paper is structured as follows: Section $\square$ provides information on the mutual fund data used here; Section 3 describes unconditional and conditional versions of the factor models used to estimate abnormal fund returns; Section 4 provides our estimates of equal- and value-weighted aggregate performance of U.S. mutual funds as well as our estimates of the cross-section distribution of $t(\alpha)$ estimates and the simulated version using unconditional asset pricing models; Section 51 provides our estimate of the crosssection distribution of $t(\alpha)$ estimates and the simulated version produced using conditional versions of these models; Section [6 uses data from January 1984 to December 2018 to update estimates and simulations of the cross-section distribution of $t(\alpha)$ using conditional models; Section 7 estimates the cross-section distribution of $t(\alpha)$ estimates yet again but controls for the Dot-com crash and the 2008 Financial Crises, as well as looking at different sub-periods of time; Section 8 suggests some regulatory changes as well as changes to fund manager compensation that would better align managerial incentives with the interest of investors; and Section 9 concludes. Appendix $\mathbb{A}$ provides information on how to construct the mutual fund dataset used here which reconstructs the data used by F\&F; and Appendix $\mathbb{B}$ tabulates the cross-section distribution of $t(\alpha)$ using unconditional 3F-CAPM when funds have at least sixteen months of returns data.

\section{The mutual fund data}

The mutual fund data used here closely follows that used by F\&F, who use the CRSP (Centre for Research in Security Prices) survivor-bias free mutual fund database. Fund information is obtained from the following three CRSP datasets: Fund Summary, Monthly Returns and Portfolio Holdings. The first of these dataset contains variables such as fund identifier (crsp_fundno), fund name, styles (referred to as Lipper or CRSP or Wiesenberger or Strategic Insight objective codes), expense ratio (exp_ratio), calender date (caldt), fund index flag (index_fund_flag) as well as other variables. Contained within the Monthly

\footnotetext{
${ }^{3}$ See Ferson and Schadt (1996) equation (7) on page 432 for the bias that is introduced by estimating unconditional asset pricing models when conditional ones are appropriate.
} 
Returns dataset are the following variables: fund return ( $m r e t)$, net asset value per share ( mnav) as well as total net asset value (mtna) according to fund identifier (crsp_fundno) and monthly calendar date (caldt). The third dataset is used to obtain information on security holdings recorded as a percentage of total net asset value (percent_tna). Datasets can be linked using the variable crsp_fundno, as each one of them contains that variable.

Like F\&F's data, our data includes funds that invest primarily in U.S. common stocks and excludes index and hedge funds. Monthly fund returns are calculated by combining value weighted returns of a fund's share classes, as is also done by F\&F. Their data spans the years January 1984 to September 2006, which allows them to include 3156 actively managed mutual funds with at least eight months of returns. Our data follows this time period but contains 3174 funds with at least eight months of returns. In a later section of this paper, we provide an up-to-date to December 2018 estimate of the cross-section distribution of the performance measure, as seen in Table III provided by F\&F. To do this, the earlier period of fund data is combined with fund data from October 2006 to December 2018. Like F\&F do, we also reduce the effects of incubation bias by following the same procedure they implement. This involves including only those funds that reach $\$ 5$ million AUM in 2006 U.S. dollars. Likewise, we set this AUM bound to $\$ 6$ million in 2018 U.S. dollars for our updated fund data. This AUM bound is adjusted each year according to inflation rates, e.g. a fund is included in 1984, if it reaches a $\$ 2.5$ million AUM bound. A more detailed account of how the mutual fund data used here is constructed can be found in Appendix 囚 of this paper.

\section{Conditional and unconditional asset pricing models}

Ferson and Schadt (1996) $)^{\text {I] }}$ construct a multiple-factor asset pricing model in which coefficients of all the factors are allowed to be a function of lagged information variables. Their equation easily accommodates simpler representations which are frequently used in the mutual fund literature. In particular, one can construct three- and four-factor asset pricing models (hereafter 3F-CAPM and 4F-CAPM) with a market-risk coefficient that is linearly related to lagged information variables ${ }^{5}$ to obtain the three factor conditional asset pricing model estimated here. For example, Barras et al $(2010)^{\mathbb{6}}$ use a specification of this form. Cuthbertson et al (2008), on the other hand, use conditional models which allow coefficients of all the factors to be linear functions of public information variables. If we also use this more general specification then it would require funds to have at least thirty six months of returns, a specification followed by Cuthbertson et al. (2008). Because our data uses funds with at least eight months of returns, we choose to follow the specification of Barras et al. (2010), and not that of Cuthbertson et al. (2008). Using the specification of the former authors does not significantly reduce the number of funds in our fund data. This prevents confounding our results with survivorship bias which would hinder comparison of our results with those of $F \& F$.

Our first set of estimations and simulations use unconditional 3F- and 4F-CAPM to produce estimates

\footnotetext{
${ }^{4}$ Combined, the Investment-Company-Institute (2018) and Investment-Company-Institute (2019) Fact Books, in 2007, report (cf. pages 42 and 40) that actively managed mutual funds represent 84\% (of USD 9.5 trillion) of total net assets of this industry, while Index funds and ETFs represent the remaining. By 2018, the former had fallen to 64\%(of USD 18 trillion), while the latter had risen to $36 \%$ of total net assets. Also following from these Fact Books is that the asset weighted expense ratio of actively managed equity mutual funds fell over this period. In 2003 it was at $1.1 \%$, by 2018 it had fallen to $0.75 \%$ (cf. page 123 of Investment-Company-Institute (2019)). Reductions of this magnitude reveal a loss in popularity of actively managed funds among investors. Nevertheless, actively managed funds still represent the majority of net assets managed by this industry, now though, with much lower expense ratios. The latter effect may improve net fund returns and possibly increase measures of fund performance based on net returns. Both factors provide support for the important role of conditional asset pricing models in assessing their performance, now as well as the foreseeable future.

${ }^{5}$ Set $\beta_{4, i}=\beta_{6, i}=\beta_{7, i}=\beta_{8, i}=0$ or $\beta_{6, i}=\beta_{7, i}=\beta_{8, i}=0$ to obtain 3F- and 4F-CAPM conditional factor models, respectively, with only a time-varying beta corresponding to the market risk factor that are estimated in this study.

${ }^{6}$ See equation 10 on page 193 of Barras et al. (2010).
} 
of the cross-section of the performance distribution. We do this to facilitate comparison of our results with those on page 1925 of $F \& F$ because we want to show that our fund data is the same as theirs. In our simulations that use more general equilibrium asset pricing models, we show the results produced using the 3F-CAPM but not those of produce using the 4F-CAPM as they are similar. The most general asset pricing model we consider is 4F-CAPM of Ferson and Schadt (1996), which contains the three factor version as a special case, is detailed below:

$$
\begin{aligned}
R_{i, t}-R_{t}^{f} & =\alpha_{i}+\beta_{1, i}\left(R_{t}^{m}-R_{t}^{f}\right)+\beta_{2, i} S M B_{t}+\beta_{3, i} H M L_{t}+\beta_{4, i} M O M_{t} \\
& +B_{5, i}^{\prime}\left(Z_{t-1}-\bar{Z}\right)\left(R_{t}^{m}-R_{t}^{f}\right)+B_{6, i}^{\prime}\left(Z_{t-1}-\bar{Z}\right) S M B_{t} \\
& +B_{7, i}^{\prime}\left(Z_{t-1}-\bar{Z}\right) H M L_{t}+B_{8, i}^{\prime}\left(Z_{t-1}-\bar{Z}\right) M O M_{t}+\varepsilon_{i, t} .
\end{aligned}
$$

Here, we adopt the same notation used by F\&F: $R_{i t}$ is the return on fund $i$ for month $t, R_{t}^{f}$ is the risk-free rate proxied by the 1-month U.S. Treasury bill rate, $R_{t}^{m}$ is the market return on the variable weighted portfolio consisting of NYSE, Amex and NASDAQ stocks along with the three factors: $S M B_{t}, H M L_{t}$ and $M O M_{t}$. The $\alpha_{i}$ of the model represents the average return left unexplained by the benchmark model. For information on theses factors see Fama and French (1993) regarding the former two and F\&F for the latter one. $Z_{t-1}$ denotes a $J \times 1$ vector of predictive variables measured at the end of month $t-1, \bar{Z}$ is their mean and $B_{5, i}$ is the $J \times 1$ vector of coefficients. In equation (1), the intercept is assumed to be constant which is consistent with the model of manager skill developed by Berk and Green (2004). Our choice of conditioning variables follows Barras et al. (2010) who use the 1-month T-bill yield; the dividend yield for the value-weighted NYSE/Amex stock index; the term spread; and the default spread ${ }^{\square}$.

There are two interesting implications gleaned from equation (四), both noted here because they have important consequences for our estimations and simulations that occur in subsequent sections. By restricting the relationship between the public information variables and the market-risk coefficient to be linear, it implies that the 4F-CAPM equation becomes a linear model with constant coefficients. An interesting byproduct of this is that the unconditional 3F-CAPM and 4F-CAPM, both used by F\&F, nest within the linear version of the conditional model of Ferson and Schadt (1996). The second implication refers the appropriate vector of conditioning variables, which at time $t$, are $\left(R_{t}^{m}-R_{t}^{f}, S M B_{t}, H M L_{t}, M O M_{t},\left(Z_{t-1}-\bar{Z}\right)\left(R_{t}^{m}-R_{t}^{f}\right)\right)$. This vector will be denoted $X_{t}$. This shows that the appropriate conditioning vector includes the lagged public information variables as well as the interaction term. And when it does, the asset pricing model now has constant parameters.

F\&F assess aggregate U.S. mutual fund performance from an equilibrium accounting perspective which has implications for the parameters of unconditional versions of (1). Forming aggregate equaland value-weighted portfolios of active funds, they estimate unconditional versions of the 3F-CAPM and 4F-CAPM. The four-factor version is given below:

$$
R_{t}-R_{t}^{f}=\alpha+\beta_{1}\left(R_{t}^{m}-R_{t}^{f}\right)+\beta_{2} S M B_{t}+\beta_{3} H M L_{t}+\beta_{4} M O M_{t}+\varepsilon_{t} .
$$

They also estimate fund level regressions using equation (2) as well as its 3F-CAPM counterpart. But in this situation, fund returns are indexed by $i$ as are the intercepts, $\alpha_{i}$, and slope coefficients, $\beta_{1, i}, \ldots, \beta_{4, i}$ to indicate the fund.

\footnotetext{
${ }^{7}$ See page 193 of Barras et al (2010).
} 


\section{Results from estimating aggregate level regressions}

Because $F \& F$ examine fund performance from the perspective of equilibrium accounting, they estimate equal-weighted $(\mathrm{EW})^{\mathbf{8}}$ and value-weighted $(\mathrm{VW})^{\mathbb{Q}}$ aggregate return level regressions to determine whether funds on average produce abnormal returns and whether aggregate wealth invested in funds produces abnormal returns. Our results from estimating versions of equation (2), ranging from the one-factor to the four-factor using both gross and net returns, are listed in Table 1 . F\&F are primarily concerned with the 3F-CAPM for their analysis so we begin our discussion with that model and then end with a brief discussion of the 4F-CAPM. To facilitate comparison with the corresponding results of F\&F, their Table II can be found in the bottom half of Table 1 .

According to EW returns, our estimates, on a net and gross returns basis, of the abnormal returns (the intercept of these models) are -1.03 and 0.37 respectively. The former estimate, when compared to the corresponding estimates of $F \& F$, is slightly smaller but statistically significant just as it is with $F \& F$, while the latter estimate is larger. Our latter estimate is statistically insignificant which corresponds with of $F \& F$. Comparing estimates of the market-risk coefficients, our estimate of 0.94 , is smaller than the estimate of $F \& F$, their estimate is 0.98 . Regarding estimates of the two remaining coefficients, there is also close agreement. Our estimate of the coefficient on $S M B$ is 0.20 which is statistically significant and similar to the corresponding estimate of $F \& F$.

Turning to VW returns and focusing on the 3F-CAPM, our estimates of abnormal returns are negative and statistically significant, as they are for F\&F, but are slightly smaller than theirs. Our estimate of 0.95 for the market-risk factor is almost the same as the estimate of F\&F which is 0.96 . Estimates of the coefficients on the two remaining factors, we find only the $S M B$ to be statistically significant just as it is for $F \& F$, with our estimate slightly larger than theirs.

Much of the similarities between our results and those of $F \& F$ that are reported above continue to hold for the 4F-CAPM. There are, though, two exceptions to this which relate to our estimates of the coefficients of $H M L$ and $M O M$ factors. On net and gross returns basis, our estimates are nearly zero which is similar to those of F\&F. Ours, though, are statistically insignificant when theirs are not. More importantly, our results reported in Table 1 confirm the observations of F\&F:

$\alpha$ estimates for $\mathrm{VW}$ gross fund returns are close to zero returns..........WW fund returns shows little exposure to the size, value and momentum strategy, and that the market return explains alone explains $99 \%$ of the variance of the monthly VW fund return ${ }^{10}$.

Table 1 also allows us to come to the same conclusion as F\&F regarding active management: "that on average, active mutual funds do not produce gross returns above (or below) those of passive benchmarks". [1] This may be due to the poor performance of unskilled managers offsetting the good performance of skilled managers. This leads us, as it did in $F \& F$, to simulations that use individual fund returns to infer the existence of superior and inferior managers.

\section{Estimating and simulating the cross-section of true $\alpha$}

The estimations and simulations we perform follow those discussed in Section III of F\&F whose intention is to make inferences about the cross-section of true $\alpha$ for actively managed mutual funds. Because true $\alpha$ is unobserved, they use the cross-section of $\alpha$ estimates obtained from estimating equation (Z) as well as its three factor version to determine whether true $\alpha$ is zero for all funds or whether it is nonzero for

\footnotetext{
${ }^{8} \mathrm{EW}$ portfolio weights fund returns equally each month.

${ }^{9} \mathrm{VW}$ portfolio weights fund returns by assets under management (AUM) at the beginning of the month.

${ }^{10}$ Fama and French (2010) page 1921.

${ }^{11}$ Ibid page 1923.
} 
a subset of funds that exists in the tails of this distribution. To be more precise, they use the precision adjusted $\alpha$ estimates, i.e. the $t(\alpha)^{[12}$, to assess fund performance rather than estimated $\alpha$. F\&F are interested in answering this question for 12 different cross-sections of $\alpha$ estimates: for gross and net returns, for three- and four-factor asset pricing models, and for three asset under management (AUM) groups. We follow the approach of F\&F and also estimate versions of (D) on gross and on net returns but focus mainly on the 3F-CAPM results, as do F\&F, because the results from estimating the 4F-CAPM are much the same.

We, like $\mathrm{F} \& \mathrm{~F}$, test for nonzero true $\alpha$ in the cross-section of true $\alpha$ for actively managed funds. Our tests, like theirs, use bootstrap simulations on returns with zero true $\alpha$. This is achieved by subtracting a funds estimated $\alpha$ from its returns where the estimated $\alpha$ is obtained by estimating the 3F- and 4F-CAPM. Estimations are carried out on net and on gross returns as well as for the asset groups: $\$ 5$ million $^{\mathbb{1 1 3}}, \$ 250$ million and $\$ 1$ billion. A simulation run consists of a random sample with replacement from the 273 months that span January 1984 to September 2006 of benchmark-adjusted returns and the corresponding vector $X_{t_{m}}$ consisting of time $t_{m}$ factors and may include the lagged $t_{m}-1$ information variables as well should equation (团) be estimated. Here, $t_{m}$ refers to one of 273 months that are randomly sampled in a simulation run.

Each asset group and benchmark-adjusted returns as well as unconditional and conditional 3F-CAPM are estimated, fund by fund, on one random sample of the 273 months. We note that the only adjustment we make to the resampling procedure used by $F \& F$ is to randomly sampling the benchmark-adjusted returns as well as the vector $X_{t_{m}}$ which includes the lagged information variables, i.e. $\left(Z_{t_{m}-1}-\bar{Z}\right)\left(R_{t_{m}}^{m}-\right.$ $R_{t_{m}}^{f}$ ). A run therefore produces a simulated cross-section of $t(\alpha)$ estimates for each of the benchmark adjusted returns, asset group and version of equation (团) using the same random sample of months. For a particular run, the percentiles of the simulated $t(\alpha)$ estimates are calculated. Corresponding percentiles are averaged across the 10,000 simulations to construct average percentiles corresponding to the cross-section of $t(\alpha)$ estimates for a world were true $\alpha$ is zero.

5.1 Results from estimating and simulating the cross-section of true $\alpha$ using the models of Fama and French (1993) and Carhart (1997)

Our first set of estimations and simulations produce the cross-sections $t(\alpha)$ estimates as well their simulated versions. Here, we use the mutual fund data we constructed to estimate the 3F- and 4F-CAPM for each of net and gross returns as well as for the three different asset groups. Results are reported in Table 2 which we compare to Table III of F\& $\mathrm{F}^{\mathbb{1 4}}$. The column headed Pct refers to the percentiles of the $t(\alpha)$ estimates; Sim refers to the percentiles of the simulated cross-section of $t(\alpha)$ estimates; $\%<$ Act refers to the percentage of simulated percentiles that are smaller than the corresponding estimated $t(\alpha)$ percentiles. Since $F \& F$ focus on the funds with more than $\$ 5$ million assets under management (AUM), we limit the discussion below to that AUM ${ }^{\mathbb{1 5}}$. Because F\&F focus on the 3F-CAPM, the discussion that follows also focuses on results produced using this model; a brief summary of the same estimates and simulations but produced using the 4F-CAPM follows at the end of this section.

We compare, on a net returns basis, our estimates of the percentiles of the distribution of $t(\alpha)$ estimates with those produced by F\&F. These are recorded in Table $\square$ under the column header Act. The first percentile is -4.00 which is slightly smaller than the -3.87 reported by F\&F (see Table III on page 1927 of $F \& F$ ). For the second percentile, ours lists as -3.53 , whereas it is -3.42 for $F \& F$. The 3rd, 4th and 5th percentiles are more closely aligned with the estimates of F\&F; our estimate of the fifth

\footnotetext{
${ }^{12}$ Fama and French (2010), on the last paragraph of page 1924, provide an explanation for using the $t(\alpha)$.

${ }^{13}$ This group consists of funds with at least $\$ 5$ million of AUM.

${ }^{14}$ Table III is located on page 1927 of F\&F.

${ }^{15}$ The two remaining AUMs are not discussed because F\&F limit their discussion to funds having at least $\$ 5$ millon assets under management.
} 
Table 1:

Intercepts and Slopes in Variants of the CAPM for Equal-Weight (EW) and Value-Weight (VW) Portfolios of Actively Managed Mutual Funds (1984-2006)

This table provides the annualized intercepts $\left(12^{*} \hat{\alpha}\right)$ and $t$-statistics for the intercepts $(t(C o e f))$ for the CAPM, the $3 \mathrm{~F}$ CAPM, and the 4F-CAPM estimated on an equal-weight (EW) and value-weight (VW) portfolio, and on net and gross returns based on a panel of actively managed mutual funds that invest mainly in equities. Regressions slopes $(b, s, h$, and $m$ ) for the corresponding factors $\left(R^{m}-R^{f}, S M B, H M L\right.$, and $\left.M O M\right)$ are also shown in the table. It should be noted that for the market slope, $t$ (Coef) tests the null hypothesis that $b$ is equal to 1 . Net returns are returns reported in the CRSP mutual fund database, and the gross returns are net returns plus $1 / 12^{\text {th }}$ of a fund's expense ratio at that year end. When a fund's expense ratio for a year is missing, we replace it with the expense ratio of the fund that has the same investment style and has similar assets under management (AUM). As for those funds with zero expense ratios, we manually check some of their annual reports and confirm that they in fact have positive expense ratios. Hence, we treat zero expense ratios as missing values. Our sample covers the period from January 1984 to September 2006 . There are 1360 funds on average every month and their average AUM is $\$ 705$ million.

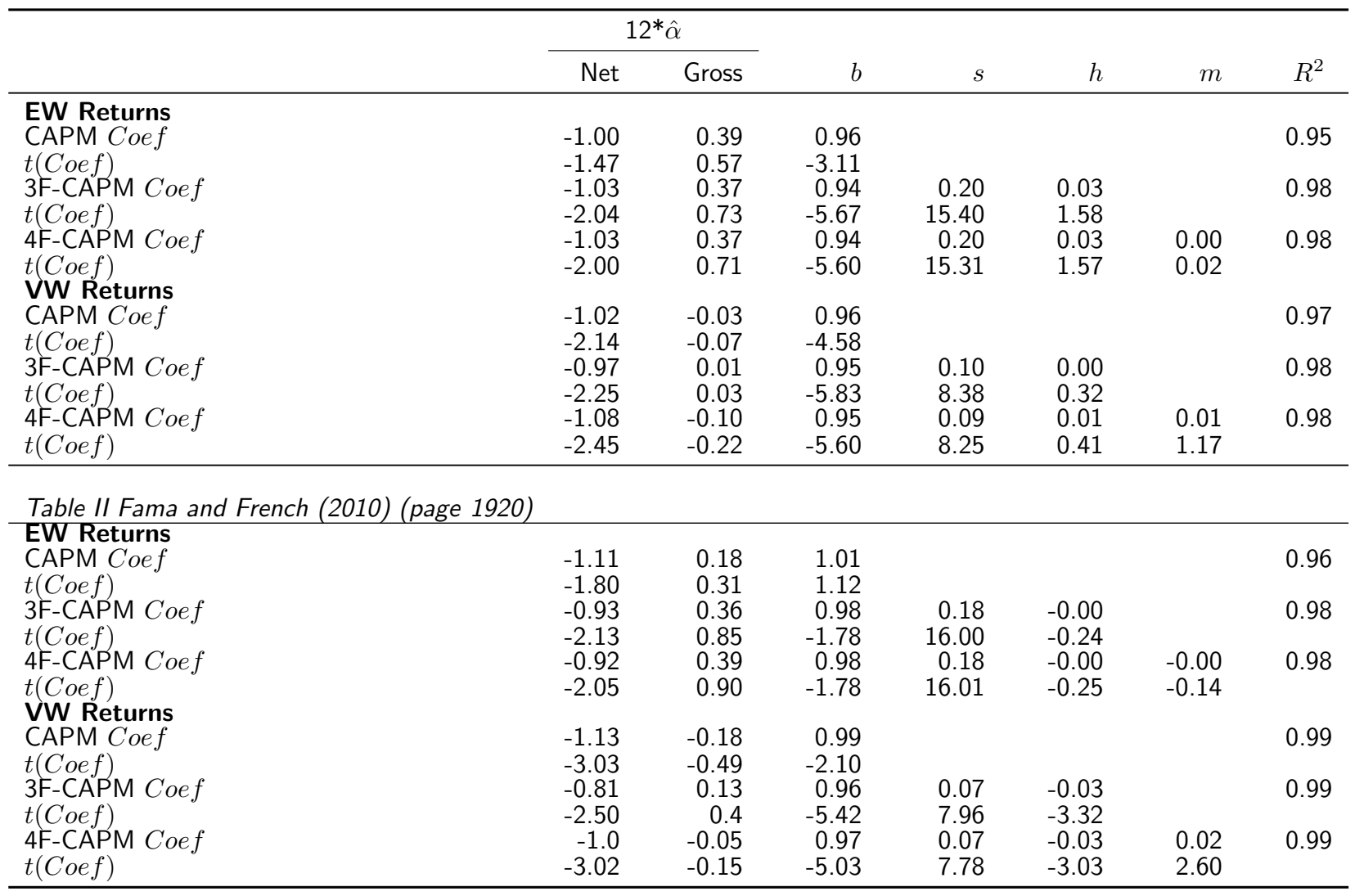

percentile is -2.89 whereas that of $F \& F$ is -2.84 , which is a difference of only 0.05 . As to the larger percentiles, i.e. 10th to 99 th, we find our estimates differ from $F \& F$ by no more than 0.04 . As such, we conclude, on a net returns basis, percentiles we estimate of the cross-section of $t(\alpha)$ estimates are virtually the same as the estimates produced by F\&F.

Turning to the simulated percentiles (see column headed Sim of Table $\mathbb{Z}$ ), our percentiles are slightly larger than those produced by F\&F. For example, their estimate of the 1st percentile is -2.50 while our estimate is -2.39 . At the 2 nd percentile, their estimate is -2.17 while ours is -2.08 . By the 10th percentile, the difference between our estimate and those of F\&F is 0.04 . The third column of Table 2 (i.e. $\%<$ Act) records the percentages of simulated $t(\alpha)$ percentiles (each run of the simulation produces one set of simulated $t(\alpha)$ percentiles) that are less than corresponding percentiles of $t(\alpha)$ estimates. Our calculations of these percentages also correspond closely to those produced by F\&F. Generally, our percentages are slightly smaller in the left tail of the distribution of $t(\alpha)$ estimates and slightly larger in 
the right tail. F\&F, in their discussion of their Table III, focus on the 3F-CAPM. Following them, we also focus our discussion our estimates of these different percentiles produced from the 3F-CAPM. 16

Comparing, on a gross return basis, our estimations and simulations with those of $F \& F$, we find that our $t(\alpha)$ estimates and simulated versions are also similar. For example, percentiles of $t(\alpha)$ estimates (see column Act of Table 2 3F-CAPM Gross Returns) from the 3rd to the 97 th differ by no more than 0.04 from the corresponding percentiles of F\&F. Our first and second percentiles differ by 0.09 and 0.07 respectively, while the 98th and 99th differ by 0.1 and 0.04 respectively. Regarding the percentiles of simulated $t(\alpha)$, our estimates are smaller than those produced by $\mathrm{F} \& \mathrm{~F}$. For example, the first to fourth percentiles that we produce differ by at most 0.1 from those of $F \& F$, with the largest deviation occurring at the first percentile. By the fifth percentile, this difference falls to 0.06 . Percentiles in the right tale of this distribution differ by at most 0.03 from the corresponding percentiles of F\&F. A similar statement can be made regarding the percentages recorded in the column $\%<$ Act. The percentages we find in the left and right tails of this distribution are slightly smaller than the corresponding results of $F \& F$ (the largest difference between our percentages and those of F\&F's is 0.81 which occurs at the 99th percentile). The cross-section of estimated and simulated $t(\alpha)$ that we obtain using the 4F-CAPM are also similar to those produced by $\mathrm{F} \& \mathrm{~F}^{[17]}$.

Because of the striking similarities between our results in Table $\square$ and the results in Table III of F\&F, we conclude that the mutual fund data we constructed consists of almost the same funds as F\&F. From this similarity, we can also conclude, as F\&F do, on a net return basis there is little evidence of funds with positive alpha that is not due to luck and there are funds with negative alpha that is not due to luck. The latter funds are truly poorly managed. On a gross returns basis, we find, as do F\&F, that funds from the 80th percentile on wards have positive alpha and therefore can cover their trading costs. However there are some funds with negative alpha that cannot cover their trading costs.

\subsection{Estimating and simulating the cross-section distribution of true/zero alpha using the condi-} tional CAPM of Ferson and Schadt (1996)

This section looks at estimating the conditional 3F-CAPM ${ }^{[18}$ on each fund in a particular AUM group in our estimations and simulations of the cross-section distribution of true/zero $\alpha$ for that AUM. Here, though, we use equation (团) which allows the coefficient of the market risk factor to be a linear function of lagged information variables. Table 3 details the results from these estimations and simulations on net and gross returns for each of the three AUM groups ${ }^{\mathbb{1 0}}$ We compare our results in Table 3 with Table III of F\&F first on net returns and then on gross returns. Much of our analysis provided below follows in a similar fashion to $F \& F$, who focus their discussion on funds with at least $\$ 5$ million AUM.

Comparing the 1st through 60th percentile of the cross-section distribution of $t(\alpha)$ estimates with those of $F \& F$, we find ours are virtually the same as theirs. For example, the first four percentiles in our table range from -3.89 (see column header Act in Table B) for the 1st to -3.06 for the 4th whereas F\&F

\footnotetext{
${ }^{16}$ For the $\$ 250$ million and $\$ 1$ billion AUM groups, our estimates, using the 4F-CAPM, of the percentiles in the extreme right tail of those two groups are somewhat different than the corresponding percentiles of F\&F. Nevertheless, the results we produce for these two AUMs are consistent with those of F\&F who find little evidence of mutual funds producing positive alpha on a net returns basis, a conclusion our results support.

${ }^{17}$ For example, our estimate of the 1 st percentile from the distribution of $t(\alpha)$ estimates is 0.17 points smaller than F\&F; our second percentile is 0.02 points larger than theirs with the remaining differing by no more than 0.04 .

${ }^{18}$ We provide the results using the 3F-CAPM because results from the 4F-CAPM are virtually the same.

${ }^{19}$ The number of funds in our estimation of Ferson and Schadt (1996) falls from 3174 to 2961 due to the larger number of parameters to estimate in this model. The information variables introduce four extra variables which cannot be estimated accurately when funds have 8 months of returns. To overcome this problem, we require funds to have at least 16 months of returns which reduces the number of funds in our sample from 3174 to 2961 . Appendix B repeats Table III of F\&F but now using only 2961 fund with at least 16 months of returns. We report that there are few very small changes in the percentiles but the conclusions regarding fund performance are the same as those of F\&F. Hence results reported in Table 3 are not due the smaller number funds but must be due to the model of Ferson and Schadt (1996).
} 
Table 2: Replication of Table III of Fama and French (2010) using unconditional 3F- and 4FCAPM: Percentiles of Actual and Simulated $t(\alpha)$ Estimates from 1984 to 2006

This table lists the percentiles (Pct), the percentiles corresponding to the cross-section distribution of estimated $t(\alpha)$ (Act) and the averaged, across the 10,000 simulation runs, percentiles of simulated $t(\alpha)(\mathrm{Sim})$. Also listed are the percentage of simulated $t(\alpha)$ percentiles that are smaller than the $t(\alpha)$ percentiles $(\%<$ Act). We employ the bootstrap of $\mathrm{F} \& \mathrm{~F}$ by resampling fund and factor returns as a pair. The sample covers the period from January 1984 to September 2006 . Results are shown for the 3F-CAPM and the 4F-CAPM, for the $\$ 5$ million, $\$ 250$ million, and $\$ 1$ billion AUM groups. There are 3174 funds in the $\$ 5$ million group, 1466 funds in the $\$ 250$ million group, and 686 funds in the $\$ 1$ billion group.

\begin{tabular}{|c|c|c|c|c|c|c|c|c|c|}
\hline \multirow[b]{2}{*}{ Pct } & \multicolumn{3}{|c|}{5 Million } & \multicolumn{3}{|c|}{250 Million } & \multicolumn{3}{|c|}{1 Billion } \\
\hline & Act & Sim & $\%<$ Act & Act & Sim & $\%<$ Act & Act & Sim & $\%<$ Act \\
\hline \multicolumn{10}{|c|}{ 3F-CAPM, Net Returns } \\
\hline 1 & -4.00 & -2.39 & & & & & & -2.51 & \\
\hline $\begin{array}{l}2 \\
3\end{array}$ & $\begin{array}{l}-3.53 \\
-3.23\end{array}$ & $\begin{array}{l}-2.08 \\
-1.90\end{array}$ & $\begin{array}{l}0.01 \\
0.01\end{array}$ & $\begin{array}{l}-3.32 \\
-3.12\end{array}$ & $\begin{array}{l}-2.10 \\
-1.90\end{array}$ & $\begin{array}{l}0.20 \\
0.12\end{array}$ & $\begin{array}{l}-3.01 \\
-2.88\end{array}$ & $\begin{array}{l}-2.12 \\
-1.92\end{array}$ & $\begin{array}{l}1.27 \\
0.51\end{array}$ \\
\hline $\begin{array}{l}4 \\
5\end{array}$ & $\begin{array}{l}-3.03 \\
-2.89\end{array}$ & $\begin{array}{l}-1.76 \\
-1.65\end{array}$ & $\begin{array}{l}0.02 \\
0.02\end{array}$ & $\begin{array}{l}-2.91 \\
-2.70\end{array}$ & $\begin{array}{l}-1.76 \\
-1.65\end{array}$ & $\begin{array}{l}0.12 \\
0.15\end{array}$ & $\begin{array}{l}-2.78 \\
-2.62\end{array}$ & $\begin{array}{l}-1.78 \\
-1.66\end{array}$ & $\begin{array}{l}0.23 \\
0.27\end{array}$ \\
\hline 10 & -2.37 & -1.28 & 0.02 & -2.25 & -1.28 & 0.11 & -2.15 & -1.28 & 0.23 \\
\hline $\begin{array}{l}20 \\
30\end{array}$ & $\begin{array}{l}-1.76 \\
-128\end{array}$ & $\begin{array}{l}-0.84 \\
-0.52\end{array}$ & 0.01 & $\begin{array}{l}-1.58 \\
-1.10\end{array}$ & $\begin{array}{l}-0.84 \\
-0.52\end{array}$ & 0.12 & $\begin{array}{l}-1.52 \\
-1.05\end{array}$ & $\begin{array}{l}-0.83 \\
-0.52\end{array}$ & $\begin{array}{l}0.24 \\
0.55\end{array}$ \\
\hline 40 & -0.90 & -0.25 & 0.02 & -0.79 & $\begin{array}{l}-0.02 \\
-0.25\end{array}$ & 0.29 & $\begin{array}{l}-1.03 \\
-0.68\end{array}$ & $\begin{array}{l}-0.32 \\
-0.25\end{array}$ & $\begin{array}{l}.35 \\
1.13\end{array}$ \\
\hline 50 & -0.63 & 0.00 & 0.02 & -0.50 & 0.00 & 0.30 & -0.42 & 0.00 & 1.02 \\
\hline 70 & $\begin{array}{r}-0.27 \\
0.09\end{array}$ & 0.52 & 0.08 & $\begin{array}{r}-0.19 \\
0.12\end{array}$ & 0.52 & $\begin{array}{l}0.19 \\
1.49\end{array}$ & 0.20 & 0.52 & $\begin{array}{l}1.83 \\
4.64\end{array}$ \\
\hline $\begin{array}{l}80 \\
90\end{array}$ & $\begin{array}{l}0.48 \\
1.03\end{array}$ & $\begin{array}{l}0.84 \\
1.29\end{array}$ & $\begin{array}{r}2.04 \\
11.34\end{array}$ & $\begin{array}{l}0.46 \\
0.98\end{array}$ & $\begin{array}{l}0.83 \\
1.28\end{array}$ & $\begin{array}{l}2.51 \\
8.91\end{array}$ & $\begin{array}{l}0.52 \\
1.04\end{array}$ & $\begin{array}{l}0.84 \\
1.28\end{array}$ & $\begin{array}{r}5.43 \\
15.20\end{array}$ \\
\hline 95 & 1.53 & 1.67 & 31.84 & 1.39 & 1.66 & 14.29 & 1.42 & 1.67 & 18.50 \\
\hline 96 & 1.65 & 1.78 & 33.97 & 1.5 & 1.7 & 17. & 1. & & 35.61 \\
\hline 97 & 1.87 & 1.92 & 46.96 & 1.7. & 1.9 & 23.80 & 1.7 & 1.93 & 34. \\
\hline 98 & $\begin{array}{l}2.15 \\
2.48\end{array}$ & 2.10 & $\begin{array}{l}61.17 \\
61.96\end{array}$ & $\begin{array}{l}1.92 \\
2.93\end{array}$ & $\begin{array}{l}2.11 \\
2.44\end{array}$ & $\begin{array}{l}27.91 \\
29 \\
25\end{array}$ & $\begin{array}{l}2.05 \\
2.32\end{array}$ & 2.13 & $\begin{array}{l}44.8 \\
37.5\end{array}$ \\
\hline \multicolumn{10}{|c|}{ 4F-CAPM, Net Returns } \\
\hline 1 & -4.00 & -2.44 & 0.00 & -3.98 & -2.50 & 0.24 & -3.63 & -2.64 & 3.70 \\
\hline 2 & -3.49 & -2.11 & 0.01 & -3.24 & -2.1 & 0.1 & -3.13 & -2. & 0.90 \\
\hline 3 & -3.18 & -1.91 & 0.0 & -2.9 & -1.9 & 0.0 & -2.70 & -1.5 & 1.39 \\
\hline $\begin{array}{l}4 \\
5\end{array}$ & $\begin{array}{l}-2.95 \\
-2.77\end{array}$ & $\begin{array}{l}-1.17 \\
-1.66\end{array}$ & 0.03 & $\begin{array}{l}-2.15 \\
-2.59\end{array}$ & 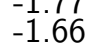 & 0.13 & -2.43 & -1. & 0.92 \\
\hline 10 & -2.27 & -1.28 & 0.01 & -2.11 & -1.27 & 0.16 & -1.95 & -1.28 & 0.88 \\
\hline 20 & -1.68 & -0.83 & 0.01 & -1.4 & -0.8 & 0.4 & -1.4 & -0.8 & 0.83 \\
\hline 30 & -1.24 & -0.51 & 0.02 & -1.08 & -0.5 & 0.56 & -1.01 & -0.51 & 1.50 \\
\hline $\begin{array}{l}40 \\
50\end{array}$ & $\begin{array}{l}-0.88 \\
-0.59\end{array}$ & $\begin{array}{r}-0.24 \\
0.01\end{array}$ & 0.06 & $\begin{array}{l}-0 . / 7 \\
-0.50\end{array}$ & $\begin{array}{r}-0.24 \\
0.01\end{array}$ & 0.74 & $\begin{array}{l}-0.11 \\
-0.39\end{array}$ & -0.24 & $\begin{array}{l}1.61 \\
2.59\end{array}$ \\
\hline 60 & -0.31 & 0.26 & 0.08 & -0.22 & 0.2 & 0.85 & $\begin{array}{l}-0.09 \\
-\end{array}$ & 0.26 & 4.24 \\
\hline 70 & 0.00 & 0.5 & 0.1. & 0.10 & & 1.4 & 0.17 & 0.53 & 4.17 \\
\hline $\begin{array}{l}80 \\
90\end{array}$ & $\begin{array}{l}0.41 \\
102\end{array}$ & 0.86 & 0.7 & $\begin{array}{l}0.48 \\
0.97\end{array}$ & 0.8 & 3.9 & 0.61 & 0.85 & $\begin{array}{l}14.69 \\
26.23\end{array}$ \\
\hline 05 & & & & & & 2274 & & & \\
\hline 96 & 1.61 & 1.82 & 23.28 & 1.54 & $\begin{array}{l}1.80 \\
1.80\end{array}$ & 18.26 & 1.76 & 1.82 & 44.84 \\
\hline 97 & 1.83 & 1.96 & $\begin{array}{l}33.38 \\
13.02\end{array}$ & 1.64 & 1.9 & 14.1 & 1.94 & $\begin{array}{l}1.97 \\
2.19\end{array}$ & 49.07 \\
\hline प0 & 2.45 & 2.1 & 43 & . & 2.1 & 11 & 2. & 2 & $\begin{array}{l}53.41 \\
40.57\end{array}$ \\
\hline
\end{tabular}

estimate the corresponding percentiles as -3.87 and -2.99 respectively. Our estimate of the fifth percentile is -2.94 while the corresponding estimate of $F \& F$ is -2.84 , a difference of 0.10 . Our estimates of the 50th and 60th percentile are -0.61 and -0.25 respectively, while those of $F \& F$ are -0.62 and -0.29 . The closeness of this correspondence ends, though, at the 90th percentile. We estimate the 90th and 99th percentile to be 1.19 and 2.75 respectively but $F \& F$ estimate these to be 1.01 and 2.47 respectively. Both estimates are considerably smaller than ours. Turning to the simulated $t(\alpha)$ percentiles, our estimate of the 1st and 5th percentile are -2.33 and -1.64 respectively which are larger than -2.50 and -1.71 estimated by F\&F. We estimate the 98th and 99th percentiles to be 2.06 and 2.34 respectively, which are much smaller than the corresponding estimates of $F \& F$ ( 2.13 and 2.45 respectively).

Comparing corresponding percentiles across the two distributions, we find that the estimates of the 
Table Q-continued

\begin{tabular}{|c|c|c|c|c|c|c|c|c|c|}
\hline \multirow[b]{2}{*}{ Pct } & \multicolumn{3}{|c|}{5 Million } & \multicolumn{3}{|c|}{250 Million } & \multicolumn{3}{|c|}{1 Billion } \\
\hline & Act & Sim & $\%<$ Act & Act & Sim & $\%<$ Act & Act & Sim & $\%<$ Act \\
\hline \multicolumn{10}{|c|}{ 3F-CAPM, Gross Returns } \\
\hline$y$ & & & & & & & & & \\
\hline$\frac{1}{2}$ & $\begin{array}{l}-3.10 \\
-2.75\end{array}$ & $\begin{array}{l}-2.39 \\
-2.08\end{array}$ & $\begin{array}{l}1.28 \\
1.69\end{array}$ & $\begin{array}{l}-2.52 \\
-2.54\end{array}$ & -2.1 & $\begin{array}{l}8.28 \\
8.00\end{array}$ & -2.46 & -2.13 & $\begin{array}{l}24.82 \\
15.87\end{array}$ \\
\hline 3 & -2.48 & -1.90 & 2.32 & -2.33 & -1.91 & $\begin{array}{l}7.73 \\
8.07\end{array}$ & -2.21 & -1.92 & 17.21 \\
\hline $\begin{array}{l}4 \\
5\end{array}$ & $\begin{array}{l}-2.31 \\
-2.18\end{array}$ & $\begin{array}{l}-1.10 \\
-1.65\end{array}$ & 2.89 & $\begin{array}{l}-2.11 \\
-2.04\end{array}$ & $\begin{array}{l}-1.17 \\
-1.65\end{array}$ & $\begin{array}{l}8.01 \\
8.19\end{array}$ & $\begin{array}{l}-2.15 \\
-1.96\end{array}$ & $\begin{array}{l}-1 . / 8 \\
-167\end{array}$ & $\begin{array}{l}10.89 \\
14.12\end{array}$ \\
\hline 10 & -1.72 & -1.28 & 3.91 & -1.60 & -1.28 & 9.64 & -1.57 & -1.28 & 12.59 \\
\hline $\begin{array}{l}20 \\
30\end{array}$ & -1.11 & -0.84 & $\begin{array}{r}9.32 \\
21.19\end{array}$ & $\begin{array}{l}-0.99 \\
-0.58\end{array}$ & -0.84 & $\begin{array}{l}22.92 \\
37.06\end{array}$ & $\begin{array}{l}-1.00 \\
-0.57\end{array}$ & $\begin{array}{l}-0.84 \\
-0.52\end{array}$ & $\begin{array}{l}22.53 \\
38.82\end{array}$ \\
\hline 40 & $\begin{array}{l}-0.01 \\
-0.35\end{array}$ & -0.25 & 28.79 & $\begin{array}{l}-0.28 \\
-0.28\end{array}$ & $\begin{array}{l}-0.02 \\
-0.25\end{array}$ & $\begin{array}{l}43.38 \\
43.38\end{array}$ & $\begin{array}{l}-0.01 \\
-0.19\end{array}$ & $\begin{array}{l}-0.02 \\
-0.25\end{array}$ & $\begin{array}{l}61.85 \\
61.02\end{array}$ \\
\hline 50 & $\begin{array}{r}-0.03 \\
-0.31\end{array}$ & 0.00 & 43.86 & 0.03 & 0.00 & 58.27 & 0.05 & -0.01 & 61.70 \\
\hline 70 & 0.65 & 0.53 & $\begin{array}{l}02.95 \\
75.74\end{array}$ & 0.61 & $\begin{array}{l}0.25 \\
0.52\end{array}$ & $\begin{array}{l}22.52 \\
68.86\end{array}$ & $\begin{array}{l}0.38 \\
0.66\end{array}$ & $\begin{array}{l}0.24 \\
0.51\end{array}$ & $\begin{array}{l}7.52 \\
78.33\end{array}$ \\
\hline $\begin{array}{l}80 \\
90\end{array}$ & $\begin{array}{l}1.03 \\
1.58\end{array}$ & $\begin{array}{l}0.85 \\
1.29\end{array}$ & $\begin{array}{l}82.20 \\
89.35\end{array}$ & $\begin{array}{l}0.96 \\
150\end{array}$ & $\begin{array}{l}0.84 \\
1.28\end{array}$ & $\begin{array}{l}73.62 \\
82.76\end{array}$ & $\begin{array}{l}0.95 \\
1.47\end{array}$ & $\begin{array}{l}0.8 \overline{3} \\
1.28\end{array}$ & $\begin{array}{l}73.38 \\
78.95\end{array}$ \\
\hline 95 & 2.04 & 1.67 & 92.88 & 1.92 & 1.66 & 83.66 & 1.94 & 1.66 & 83.89 \\
\hline 96 & 2.18 & 1.78 & 93.43 & 2.06 & 1.78 & 85.33 & 2.06 & 1.78 & 83.57 \\
\hline 97 & 2.40 & 1.92 & 95.04 & 2.26 & 1.92 & 88.13 & 2.29 & 1.92 & 88.41 \\
\hline 99 & 2.09 & 2.41 & 95.85 & 2.80 & 2.4 & 85. & 2. & 2. & 71.1 . \\
\hline \multicolumn{10}{|c|}{ 4F-CAPM, Gross Returns } \\
\hline 1 & -3.23 & -2.44 & 0.96 & & -2.5 & 18.20 & & -2.62 & 29.64 \\
\hline 2 & $\begin{array}{l}-2.73 \\
-2.46\end{array}$ & $\begin{array}{l}-2.10 \\
-1.91\end{array}$ & $\begin{array}{l}1.71 \\
2.43\end{array}$ & $\begin{array}{l}-2.50 \\
-2.22\end{array}$ & -2.1 & $\begin{array}{r}9.88 \\
13.21\end{array}$ & $\begin{array}{l}-2.30 \\
-2.02\end{array}$ & $\begin{array}{l}-2.17 \\
-1.95\end{array}$ & $\begin{array}{l}31.94 \\
38.41\end{array}$ \\
\hline 4 & -2.26 & -1.76 & 3.17 & -2.05 & -1.77 & 13.81 & -1.88 & -1.80 & 35.83 \\
\hline 5 & -2.10 & -1.65 & 4.29 & -1.92 & -1.65 & 14.27 & -1.73 & -1.68 & 39.21 \\
\hline 10 & -1.62 & -1.27 & 6.50 & -1.50 & -1.27 & 16.04 & -1.42 & -1.28 & 27.18 \\
\hline $\begin{array}{l}20 \\
30\end{array}$ & $\begin{array}{l}-1.05 \\
-0.62\end{array}$ & $\begin{array}{l}-0.82 \\
-0.50\end{array}$ & $\begin{array}{l}13.76 \\
26.30\end{array}$ & $\begin{array}{l}-0.90 \\
-0.55\end{array}$ & $\begin{array}{l}-0.82 \\
-0.51\end{array}$ & $\begin{array}{l}34.57 \\
41.09\end{array}$ & $\begin{array}{l}-0.90 \\
-0.52\end{array}$ & $\begin{array}{l}-0.83 \\
-0.51\end{array}$ & $\begin{array}{l}3.30 \\
4789\end{array}$ \\
\hline 40 & -0.28 & -0.23 & 40.21 & -0.24 & -0.24 & 49.26 & -0.17 & -0.24 & 64.55 \\
\hline $\begin{array}{l}50 \\
60\end{array}$ & $\begin{array}{l}0.00 \\
0.29\end{array}$ & $\begin{array}{l}0.02 \\
0.27\end{array}$ & $\begin{array}{l}46.03 \\
56.39\end{array}$ & $\begin{array}{l}0.01 \\
0.31\end{array}$ & $\begin{array}{l}0.01 \\
0.26\end{array}$ & $\begin{array}{l}51.98 \\
62.91\end{array}$ & $\begin{array}{l}0.10 \\
0.42\end{array}$ & $\begin{array}{l}0.01 \\
0.25\end{array}$ & $\begin{array}{l}68.96 \\
79.09\end{array}$ \\
\hline 70 & 0.63 & 0.54 & 68.31 & 0.64 & 0.5 & 72.57 & 0. & 0.52 & $\begin{array}{l}76.17 \\
\end{array}$ \\
\hline $\begin{array}{l}80 \\
90\end{array}$ & $\begin{array}{l}1.01 \\
1.57\end{array}$ & $\begin{array}{l}0.86 \\
132\end{array}$ & $\begin{array}{l}77.05 \\
85.92\end{array}$ & $\begin{array}{l}0.95 \\
1.46\end{array}$ & $\begin{array}{l}0.84 \\
129\end{array}$ & $\begin{array}{l}70.11 \\
76.47\end{array}$ & 1.0 & $\begin{array}{l}0.85 \\
1.30\end{array}$ & $\begin{array}{r}85.93 \\
89.04\end{array}$ \\
\hline 95 & & & & & & & & & \\
\hline 96 & 2.20 & 1.82 & 91.95 & 2.08 & 1.8 & 85.12 & 2.2 & 1.82 & 92.24 \\
\hline $\begin{array}{l}97 \\
98\end{array}$ & $\begin{array}{l}2.3 \\
2.6\end{array}$ & $\begin{array}{l}1.9 \\
21\end{array}$ & $\begin{array}{l}92.4 \\
93.4\end{array}$ & 2.2 & $\frac{1}{2}$. & 85 & 2.3 & 2 & \\
\hline 9 & 2.99 & & 92.45 & 2.0 & 2.5 & & & 2.1 & 74.22 \\
\hline
\end{tabular}

1st to 90th percentile of $t(\alpha)$ estimates are much smaller than the corresponding percentiles of simulated $t(\alpha)$. However, the 90th to 99th percentile of the distribution of $t(\alpha)$ estimates are much larger than the corresponding simulated ones. Because of these two results, we conclude that the simulated world of zero alpha funds no longer represents the distribution of $t(\alpha)$ estimates, as it does in $\mathrm{F} \& \mathrm{~F}$. More importantly, results presented in Table 3 provide much stronger evidence than that produced by $F \& F$ on the existence of actively managed funds with positive alpha that reside in the extreme right tail of the distribution of $t(\alpha)$ estimates. Regarding the existence of funds with negative alpha, our result from estimated and simulated $t(\alpha)$ provide much stronger evidence of the existence of funds with negative alpha that reside in extreme left tail of the former distribution.

Now we turn to comparing the percentages of the 10,000 simulated $t(\alpha)$ percentiles with the percentiles of the distribution of $t(\alpha)$ estimates (see column header $\%<$ Act in Table B). Our estimates of the 90th to 99th percentiles of $t(\alpha)$ are much larger then those of F\&F, we find at the 98th percentile that $83.97 \%$ of simulated $t(\alpha)$ percentiles are smaller than the percentiles of the $t(\alpha)$ estimate. This rises to $91.37 \%$ at the 99 th percentile. The fact that almost all of the simulated percentiles (a full set of percentiles is estimated for each of the 10,000 runs) are smaller than the 99th percentile of $t(\alpha)$ estimates implies that the right tail of the distribution of $t(\alpha)$ estimates is larger than the percentiles of the distribution of simulated $t(\alpha)$ s. Hence, the simulated world where funds only have zero alpha does not produce percentiles in the extreme right tail that are as large as those of the distribution of 
Table 3: Percentiles of Actual and Simulated $t(\alpha)$ Estimates Using Ferson \& Schadt (1996) Model (CON 3F-CAPM): 1984 to 2006

This table lists the percentiles (Pct), the percentiles corresponding to the cross-section distribution of estimated $t(\alpha)$ (Act) and the averaged, across the 10,000 simulation runs, percentiles of simulated $t(\alpha)(\mathrm{Sim})$. Also listed are the percentage of simulated $t(\alpha)$ percentiles that are smaller than the $t(\alpha)$ percentiles $(\%<$ Act $)$. We bootstrap by resampling fund, factor returns and the corresponding lagged information variable as a triple. The sample covers the period from January 1984 to September 2006. Results are shown for the 3F-CAPM for the $\$ 5$ million, $\$ 250$ million, and $\$ 1$ billion AUM groups. There are 2961 funds in the $\$ 5$ million group, 1338 funds in the $\$ 250$ million group, and 609 funds in the $\$ 1$ billion group.

\begin{tabular}{|c|c|c|c|c|c|c|c|c|c|}
\hline \multirow[b]{2}{*}{ Pct } & \multicolumn{3}{|c|}{5 Million } & \multicolumn{3}{|c|}{250 Million } & \multicolumn{3}{|c|}{1 Billion } \\
\hline & Act & Sim & $\%<$ Act & Act & Sim & $\%<$ Act & Act & Sim & $\%<$ Act \\
\hline $\begin{array}{l}\text { COI } \\
1 \\
2 \\
3 \\
4 \\
5 \\
10 \\
20 \\
30 \\
40 \\
50 \\
60 \\
70 \\
80 \\
90 \\
95 \\
96 \\
97 \\
98 \\
99\end{array}$ & $\begin{array}{l}3 \text { F-CAF } \\
-3.89 \\
-3.44 \\
-3.21 \\
-3.06 \\
-2.94 \\
-2.38 \\
-1.77 \\
-1.30 \\
-0.92 \\
-0.61 \\
-0.25 \\
0.14 \\
0.58 \\
1.19 \\
1.78 \\
1.94 \\
2.12 \\
2.32 \\
2.75\end{array}$ & $\begin{array}{l}\mathrm{P}, \mathrm{Net} \\
-2.33 \\
-2.05 \\
-1.88 \\
-1.74 \\
-1.64 \\
-1.28 \\
-0.84 \\
-0.52 \\
-0.25 \\
0.00 \\
0.25 \\
0.52 \\
0.84 \\
1.27 \\
1.64 \\
1.75 \\
1.88 \\
2.06 \\
2.34\end{array}$ & $\begin{array}{r}\text { Returns } \\
0.00 \\
0.00 \\
0.00 \\
0.00 \\
0.00 \\
0.02 \\
0.02 \\
0.05 \\
0.06 \\
0.06 \\
0.37 \\
2.30 \\
10.08 \\
38.99 \\
73.90 \\
78.79 \\
82.89 \\
83.97 \\
91.37\end{array}$ & $\begin{array}{r}-3.89 \\
-3.34 \\
-3.15 \\
-2.91 \\
-2.82 \\
-2.26 \\
-1.65 \\
-1.12 \\
-0.81 \\
-0.49 \\
-0.16 \\
0.19 \\
0.53 \\
1.08 \\
1.52 \\
1.74 \\
1.89 \\
2.11 \\
2.36\end{array}$ & $\begin{array}{r}-2.31 \\
-2.04 \\
-1.87 \\
-1.74 \\
-1.63 \\
-1.27 \\
-0.83 \\
-0.52 \\
-0.25 \\
0.00 \\
0.25 \\
0.52 \\
0.83 \\
1.27 \\
1.63 \\
1.74 \\
1.87 \\
2.04 \\
2.32\end{array}$ & $\begin{array}{r}0.09 \\
0.11 \\
0.09 \\
0.10 \\
0.09 \\
0.09 \\
0.12 \\
0.42 \\
0.41 \\
0.86 \\
2.29 \\
6.10 \\
8.55 \\
24.32 \\
37.94 \\
53.90 \\
56.36 \\
61.77 \\
59.32\end{array}$ & $\begin{array}{r}-3.68 \\
-3.14 \\
-3.00 \\
-2.91 \\
-2.73 \\
-2.24 \\
-1.67 \\
-1.05 \\
-0.65 \\
-0.33 \\
0.00 \\
0.25 \\
0.60 \\
1.07 \\
1.57 \\
1.74 \\
1.98 \\
2.32 \\
2.57\end{array}$ & $\begin{array}{r}-2.33 \\
-2.06 \\
-1.87 \\
-1.75 \\
-1.63 \\
-1.27 \\
-0.84 \\
-0.52 \\
-0.26 \\
-0.01 \\
0.24 \\
0.51 \\
0.83 \\
1.26 \\
1.62 \\
1.74 \\
1.86 \\
2.06 \\
2.32\end{array}$ & $\begin{array}{r}0.18 \\
0.39 \\
0.19 \\
0.13 \\
0.18 \\
0.14 \\
0.08 \\
1.16 \\
3.49 \\
6.44 \\
11.98 \\
11.67 \\
16.00 \\
24.38 \\
46.08 \\
54.26 \\
67.56 \\
79.41 \\
76.84\end{array}$ \\
\hline $\begin{array}{l}\text { CO } \\
1 \\
2 \\
3 \\
4 \\
5 \\
10 \\
20 \\
30 \\
40 \\
50 \\
60 \\
70 \\
80 \\
90 \\
95 \\
96 \\
97 \\
98 \\
99\end{array}$ & $\begin{array}{l}3 \text { F-CAF } \\
-3.01 \\
-2.73 \\
-2.48 \\
-2.34 \\
-2.16 \\
-1.70 \\
-1.09 \\
-0.64 \\
-0.29 \\
0.04 \\
0.41 \\
0.77 \\
1.20 \\
1.75 \\
2.25 \\
2.42 \\
2.58 \\
2.81 \\
3.20\end{array}$ & $\begin{array}{l}\text { M, Gros } \\
-2.33 \\
-2.05 \\
-1.88 \\
-1.75 \\
-1.64 \\
-1.28 \\
-0.84 \\
-0.52 \\
-0.26 \\
0.00 \\
0.25 \\
0.52 \\
0.84 \\
1.27 \\
1.64 \\
1.75 \\
1.88 \\
2.06 \\
2.34\end{array}$ & $\begin{array}{c}\text { Returns } \\
1.91 \\
1.58 \\
2.05 \\
1.86 \\
2.89 \\
4.33 \\
12.09 \\
27.23 \\
43.60 \\
58.96 \\
80.43 \\
90.09 \\
95.18 \\
96.76 \\
98.23 \\
98.60 \\
98.62 \\
98.81 \\
99.14\end{array}$ & $\begin{array}{r}-2.94 \\
-2.64 \\
-2.33 \\
-2.18 \\
-2.07 \\
-1.60 \\
-0.98 \\
-0.55 \\
-0.18 \\
0.07 \\
0.41 \\
0.75 \\
1.10 \\
1.65 \\
2.07 \\
2.30 \\
2.42 \\
2.56 \\
2.93\end{array}$ & $\begin{array}{r}-2.31 \\
-2.04 \\
-1.87 \\
-1.74 \\
-1.63 \\
-1.27 \\
-0.83 \\
-0.52 \\
-0.25 \\
0.00 \\
0.25 \\
0.51 \\
0.83 \\
1.27 \\
1.63 \\
1.74 \\
1.87 \\
2.04 \\
2.31\end{array}$ & $\begin{array}{r}3.88 \\
3.38 \\
6.52 \\
6.90 \\
6.49 \\
10.37 \\
25.29 \\
43.77 \\
63.49 \\
65.16 \\
78.66 \\
85.58 \\
87.40 \\
92.87 \\
93.57 \\
96.43 \\
95.89 \\
94.18 \\
95.49\end{array}$ & $\begin{array}{r}-2.91 \\
-2.48 \\
-2.20 \\
-2.05 \\
-1.96 \\
-1.61 \\
-1.07 \\
-0.50 \\
-0.12 \\
0.19 \\
0.49 \\
0.80 \\
1.17 \\
1.60 \\
2.05 \\
2.21 \\
2.43 \\
2.74 \\
2.95\end{array}$ & $\begin{array}{r}-2.33 \\
-2.06 \\
-1.87 \\
-1.74 \\
-1.63 \\
-1.27 \\
-0.84 \\
-0.53 \\
-0.26 \\
-0.01 \\
0.24 \\
0.51 \\
0.82 \\
1.26 \\
1.62 \\
1.73 \\
1.86 \\
2.05 \\
2.32\end{array}$ & $\begin{array}{r}6.83 \\
10.52 \\
13.80 \\
15.50 \\
13.14 \\
10.30 \\
16.19 \\
52.65 \\
75.05 \\
83.10 \\
88.35 \\
91.12 \\
92.55 \\
90.20 \\
92.51 \\
93.19 \\
95.78 \\
96.80 \\
94.40\end{array}$ \\
\hline
\end{tabular}

$t(\alpha)$ estimates. In contrast, $\mathrm{F} \& \mathrm{~F}$ find that only $57.42 \%$ of the simulated $t(\alpha)$ s are smaller then the 99th percentile of $t(\alpha)$ estimates which is evidence that the distribution of simulated $t(\alpha) \mathrm{s}$ is similar to the distribution of $t(\alpha)$ estimates. Our evidence, given above, provides much stronger evidence for the existence of funds with positive alpha, which contradicts the evidence and therefore the conclusions reached by $F \& F$ on the nonexistence of funds with positive alpha. Our evidence regarding the existence of funds with negative alpha confirms their conclusion: there are a large number of funds in the extreme left tail of this distribution with negative alpha.

Regarding the 250 million and 1 Billion AUM groups, our evidence and conclusions are similar to those reached by F\&F. On a net returns basis, the likelihoods listed in the column header $\%<$ Act (see Table 3) of the simulated $t(\alpha)$ percentiles are much larger than they are for F\&F. For example, at the 98th and 99th percentiles of funds with at least 250 million AUM, we find $59.32 \%$ and $76.84 \%$ are smaller 
than the $t(\alpha)$ estimates but $\mathrm{F} \& \mathrm{~F}$ find these to be $43.92 \%$ and $63.11 \%$ respectively. Our conclusions therefore remain the same as F\&F regarding funds from this AUM: funds in the extreme right tail of the distribution of $t(\alpha)$ estimates do not produce positive alpha. Our evidence is weaker than the evidence provide by F\&F. As to the percentiles in the extreme left tail of the distribution of $t(\alpha)$ estimates, our percentiles are similar to the estimates produced by $F \& F$. Here, we conclude, as do F\&F, that funds in the extreme left of this distribution have negative alpha.

On a gross returns basis, our estimates of the percentiles of the cross-section distribution of $t(\alpha)$ are larger than those estimated by $F \& F$, a result that is to be expected when a condition factor models are used to estimate abnormal returns ${ }^{20}$. For example, we estimate the first and fifth percentile as -3.01 and -2.26 , whereas F\&F estimate these as -3.07 and -2.19 , respectively. In the extreme right tail of this distribution, our estimates of the 95th and 99th percentiles are 2.25 and 3.20 respectively, which are much larger than the corresponding estimates of F\&F (their estimates are 2.04 and 3.03 respectively). Regarding estimates of the percentiles of simulated $t(\alpha)$, where all funds have zero alpha, our estimates in the left tail of this distribution are larger than the corresponding estimates produced by F\&F. From the 10th to 90th percentile our estimates agree with F\&F (our estimates differ from those produced by F\&F by no more than 0.05 ). Turning to the extreme right tail of this distribution, our estimates are slightly smaller: the 98th and 99th percentiles are estimated as 2.06 and 2.34 respectively, while those of $F \& F$ are estimated as 2.13 and 2.45 respectively.

Turning to the two remaining AUM groups, our findings on the percentiles of estimated and simulated $t(\alpha)$ are that they follow the same pattern as those percentiles of the $\$ 5$ million group. Estimates of the percentiles in the extreme left tail of these two distributions tend to be somewhat larger than the corresponding estimates of $F \& F$. In the extreme right tail of these distributions, the percentiles from the former distribution are much larger than corresponding ones produced by F\&F, while in the latter distribution these same percentiles are smaller than the corresponding ones produced by $F \& F$. Much of this pattern can be attributed to the use of a conditional factor model to estimate abnormal fund returns, which produces larger estimates of alpha and therefore larger estimates of these percentiles. Our conclusions here are different than those of $F \& F$ who conclude funds on the extreme right tail of the latter distribution (distribution of estimated $t(\alpha)$ ) have positive alpha because they are much larger those in our simulation of $t(\alpha)$. Because they are much larger than the percentiles in the right tail, funds located there must have positive alpha. In the extreme left tail of this distribution, there is evidence of negative alpha which is similar to the findings of $F \& F$. Our conclusion, like $F \& F$, comes from the fact that the percentiles are much smaller (first to fifth percentile of the distribution of estimated $t(\alpha)$ rang from -3.89 to -2.94 whereas the corresponding percentiles of simulated $t(\alpha)$ range from -2.33 to -1.64$)$ than those that can be attributed to luck only.

\section{Up-to-date estimation of the cross-section distribution of alpha and simula- tions}

As an additional step in our analysis, we re-estimate equation (回), this time extending our sample to the latest available data (from January 1984 to December 2018). The results of these estimations are depicted in Tables 4 and 5. For ease of comparison, we present our results in a similar fashion as in F\&F, reporting both EW and VW estimation results. For ease of reference, VW returns summarize performance of aggregate wealth invested in funds, whereas EW regressions do the same but now for average performance of funds. It lists, as in Table II of F\&F (see page 1920 of F\&F), versions of the CAPM ranging from the simple one-factor CAPM to the four-factor but now includes information variables that appear in these versions as interactions with the market risk premium. Versions of the

\footnotetext{
${ }^{20}$ Ferson and Schadt (1996) show when a conditional model us used to estimate alpha, the measure of abnormal fund return, estimates are larger than those produced using unconditional factor models.
} 
Table 4:

Intercepts and Slopes in Variants of the CAPM Ferson \& Schadt conditional models for EqualWeight (EW) and Value-Weight (VW) Portfolios of Actively Managed Mutual Funds (19842018)

This table provides the annualized intercepts $\left(12^{*} \hat{\alpha}\right)$ and $t$-statistics for the intercepts $(t(C o e f))$ for the Ferson \& Schadt conditional asset pricing models of CAPM, the 3F-CAPM, and the 4F-CAPM estimated on an equal-weight (EW) and value-weight (VW) portfolio, and on net and gross returns based on a panel of actively managed mutual funds that invest mainly in equities. Regressions slopes $\left(\hat{\beta}_{1}, \hat{\beta}_{2}, \hat{\beta}_{3}\right.$, and $\left.\hat{\beta}_{4}\right)$ for the corresponding factors $\left(R^{m}-R^{f}, S M B, H M L\right.$, and $M O M)$ are shown in the table. $\hat{\beta}_{5}, \hat{\beta}_{6}, \hat{\beta}_{7}$, and $\hat{\beta}_{8}$ are coefficients for the interaction terms of the market return with the four information, 1 month T-bill rate,dividend yield on the value weighted NYSE/Amex stock index, term spread and default spread, variables introduced by Ferson \& Schadt. It should be noted that for the market slope, $t($ Coef $)$ tests the null hypothesis that $\beta$ is equal to 1 . Net returns are returns reported in the CRSP mutual fund database, and the gross returns are net returns plus $1 / 12^{\text {th }}$ of a fund's expense ratio at that year end. When a fund's expense ratio for a year is missing, we replace it with the expense ratio of the fund that has the same investment style and has similar assets under management (AUM). As for those funds with zero expense ratios, we manually check some of their annual reports and confirm that they in fact have positive expense ratios. Hence, we treat zero expense ratios as missing values. Our sample covers the period from January 1984 to December 2018. There are 1678 funds on average every month and their average AUM is $\$ 873$ million.

\begin{tabular}{lccccccccccc}
\hline & \multicolumn{3}{c}{$12^{*} \hat{\alpha}(\%)$} & & & & & & & & \\
& Net & Gross & $\hat{\beta}_{1}$ & $\hat{\beta}_{2}$ & $\hat{\beta}_{3}$ & $\hat{\beta}_{4}$ & $\hat{\beta}_{5}$ & $\hat{\beta}_{6}$ & $\hat{\beta}_{7}$ & $\hat{\beta}_{8}$ & $R^{2}$ \\
\hline VW Returns & & & & & & & & & & & \\
CAPM Coef & -1.00 & -0.03 & 0.98 & & & & -6.78 & -18.02 & 0.99 & 0.41 & 0.98 \\
$t($ Coef $)$ & -2.83 & -0.09 & -2.38 & & & & -2.01 & -1.90 & 1.40 & 0.28 & \\
3F-CAPM Coef & -0.80 & 0.16 & 0.96 & 0.08 & -0.03 & & -7.31 & -14.26 & 1.27 & 1.43 & 0.99 \\
$t($ Coef $)$ & -2.55 & 0.51 & -5.25 & 9.09 & -3.02 & & -2.36 & -1.70 & 2.01 & 1.08 & \\
4F-CAPM Coef & -0.86 & 0.10 & 0.97 & 0.08 & -0.03 & 0.01 & -7.53 & -15.05 & 1.24 & 1.86 & 0.99 \\
$t($ Coef $)$ & -2.71 & 0.32 & -5.06 & 9.00 & -2.87 & 1.24 & -2.42 & -1.79 & 1.96 & 1.36 & \\
\hline EW Returns & & & & & & & & & & & \\
CAPM Coef & -1.21 & 0.09 & 1.00 & & & & -14.05 & -20.38 & 1.04 & -0.72 & 0.96 \\
$t$ (Coef) & -2.40 & 0.18 & -0.27 & & & & -2.91 & -1.51 & 1.02 & -0.35 & \\
3F-CAPM Coef & -1.04 & 0.26 & 0.97 & 0.20 & 0.00 & & -9.85 & -13.54 & 1.29 & -0.24 & 0.98 \\
$t($ Coef $)$ & -2.90 & 0.73 & -4.37 & 19.82 & 0.08 & & -2.80 & -1.42 & 1.79 & -0.16 & \\
4F-CAPM Coef & -1.03 & 0.26 & 0.97 & 0.20 & 0.00 & 0.00 & -9.84 & -13.49 & 1.29 & -0.27 & 0.98 \\
$t($ Coef $)$ & -2.85 & 0.73 & -4.34 & 19.76 & 0.07 & -0.07 & -2.79 & -1.41 & 1.79 & -0.18 & \\
\hline
\end{tabular}

CAPM are estimated using gross as well as net returns, each displayed in the corresponding column of Table A.

Starting with a few general comments on the former table, results listed there suggest that market slopes $\left(\beta_{1}\right)$ are close to unity (ranging from 0.96 to 1.00 ) similarly and unsurprisingly they correspond to estimates listed in table of $F \& \mathrm{~F}^{[2]}$. The $H M L_{t}$ and $M O M_{t}$ slopes $\left(\beta_{3}\right.$ and $\beta_{4}$ respectively) are very close to zero ( $\beta_{4}$ is also zero, while $\beta_{3}$ is nonzero but very small for the VW returns) suggesting near-zero exposure to the value growth and momentum factors. Finally, $S M B_{t}$ is significant and positive for both VW and EW, but much larger (estimate is 0.20 ) for EW returns compared to VW returns (estimate is 0.08). Our estimates of overall fund performance, based on the intercepts of equation (1), align closely with F\&F. VW returns, on a net returns basis, find estimates of the intercept ranging from -0.80 to -1 . On a gross returns basis, estimates of the intercept range from 0.98 to $0.96^{22}$. Turning to EW returns, estimates of the intercepts, on a net returns basis, range from -1.3 to -1.21 , while on a gross returns basis range from 0.09 to 0.26 . Estimates of the intercept based on gross returns, for both VW and EW, are statistically indistinguishable from 0 .

\footnotetext{
${ }^{21} \mathrm{~F} \& \mathrm{~F}$ account for this as the aggregate portfolio consists mainly of the same US stocks as does the market return which is a value weighting of NYSE, Amex and NASDAQ stocks.

${ }^{22}$ The t-statistics reported below the estimates reject the null hypothesis that the market risk factor is 1 , a result which contrasts with the corresponding tests of F\&F. We argue this is due to the much larger number of mutual funds (1678 funds) used to obtain our estimates relatively the number used by F\&F (they use 1308 funds).
} 
Now we turn to the estimates of the coefficients associated with the information variables. In our estimations of equation (10), these variables are multiplied by the market risk premium to form interaction terms. For both VW and EW regressions, estimates associated with the one month T-bill rate and the dividend yield on the value weighted NYSE/Amex stock index are very small and negative; only the former estimate is statistically significant. Regarding the term and default spread interactions, estimates are relatively small and positive (according to the 3F-CAPM estimates are 2.01 and 1.43); neither estimate is statistically significant. Focusing on the $\mathrm{VW}$ regressions, estimates of the betas on the one month T-bill rate and dividend yield are, for the 3F- and 4F-CAPM, virtually the same; only the former estimate is statistically significant. Observations which indicate only the 1 month T-bill rate makes a significant contributing to regressions explaining the dynamics of aggregate excess fund returns, regardless of the definition of fund returns used in these regressions. In summary, when we estimate the conditional model for the full sample the estimates of the coefficients of the four factors as well as the intercepts are quite similar to those derived by F\&F, who estimate unconditional models. Thus, average fund performance (EW returns) as well as performance of aggregate wealth invested in funds (VW returns) relative to passive benchmarks remain very poor after including the informational variables in the regressions.

Turning our attention to Table 5 which presents analytical results of our estimations and simulations in a similar fashion to Table 3 but based on the full sample of years 1984 to the end of 2018 using the conditional 3F-CAPM (as given in equation (团)). Providing these results, up to date as they are, gives information on the evolution of fund performance beyond September 2006 where F\&F conclude their analysis. Our analysis that follows will give some insight into the value of actively managed funds that investing household may find useful.

F\&F focus much of their discussion on the \$5 Million AUM of their Table III, we follow their lead as well and limit most of our discussion to this AUM; a brief discussion will follow at the end of this section on the two remaining AUM groups. On a net return basis, the 1st through 60th percentile (see column header Act in Table 5) of the distribution of $t(\alpha)$ estimates bare a strikingly resemblance to corresponding percentiles of F\&F. For example, the first 10 percentiles in Table $5(t(\alpha)$ estimates under column header Act) range from -3.81 (1st) to -2.36 (10th), while the corresponding percentiles for $F \& F$ are -3.87 and -2.34 respectively. After that there is a slight difference in our estimates compared to that of $F \& F$ (for example the 20 th percentile is -1.80 compared to the $F \& F$ of $-1.74 ; 30$ th percentile is -1.40 compared to that of $F \& F$ of -1.27 and so on). These slight differences continue after the 70th percentile till the end, becoming constantly bigger for higher percentile, with positive returns ranging from 0.30 to 2.25 (compared to the corresponding values of $F \& F$ of 0.50 to 2.47).

Turning to the next column in Table 5 which lists simulated $t(\alpha)$ percentiles of the distribution of funds that have zero alpha, we compare these to the corresponding percentiles of $t(\alpha)$ estimates. The percentiles in the left tail of the former distribution are much smaller than the corresponding percentiles of the latter. This repeats throughout the left tail: percentiles of the estimated $t(\alpha)$ are much smaller than the simulated ones. For example, the 1st through 5th percentile of the estimated $t(\alpha) \mathrm{s}$ range from -3.81 to -2.08 , where as the simulated one range from -2.31 to -1.64 . 
Table 5: Percentiles of Actual and Simulated $t(\alpha)$ Estimates Using Ferson \& Schadt (1996) Model (CON 3F-CAPM: 1984 to 2018)

This table lists the percentiles (Pct), the percentiles corresponding to the cross-section distribution of estimated $t(\alpha)$ (Act) and the averaged, across the 10,000 simulation runs, percentiles of simulated $t(\alpha)(\mathrm{Sim})$. Also listed are the percentage of simulated $t(\alpha)$ percentiles that are smaller than the estimated $t(\alpha)$ percentiles $(\%<$ Act $)$. We bootstrap by resampling fund and factor returns jointly as a pair. The sample covers the period from January 1984 to December 2018. Results are shown for the unconditional 3F-CAPM for the $\$ 5$ million, $\$ 250$ million, and $\$ 1$ billion AUM groups. There are 5116 funds in the $\$ 5$ million group, 2459 funds in the $\$ 250$ million group, and 1162 funds in the $\$ 1$ billion group.

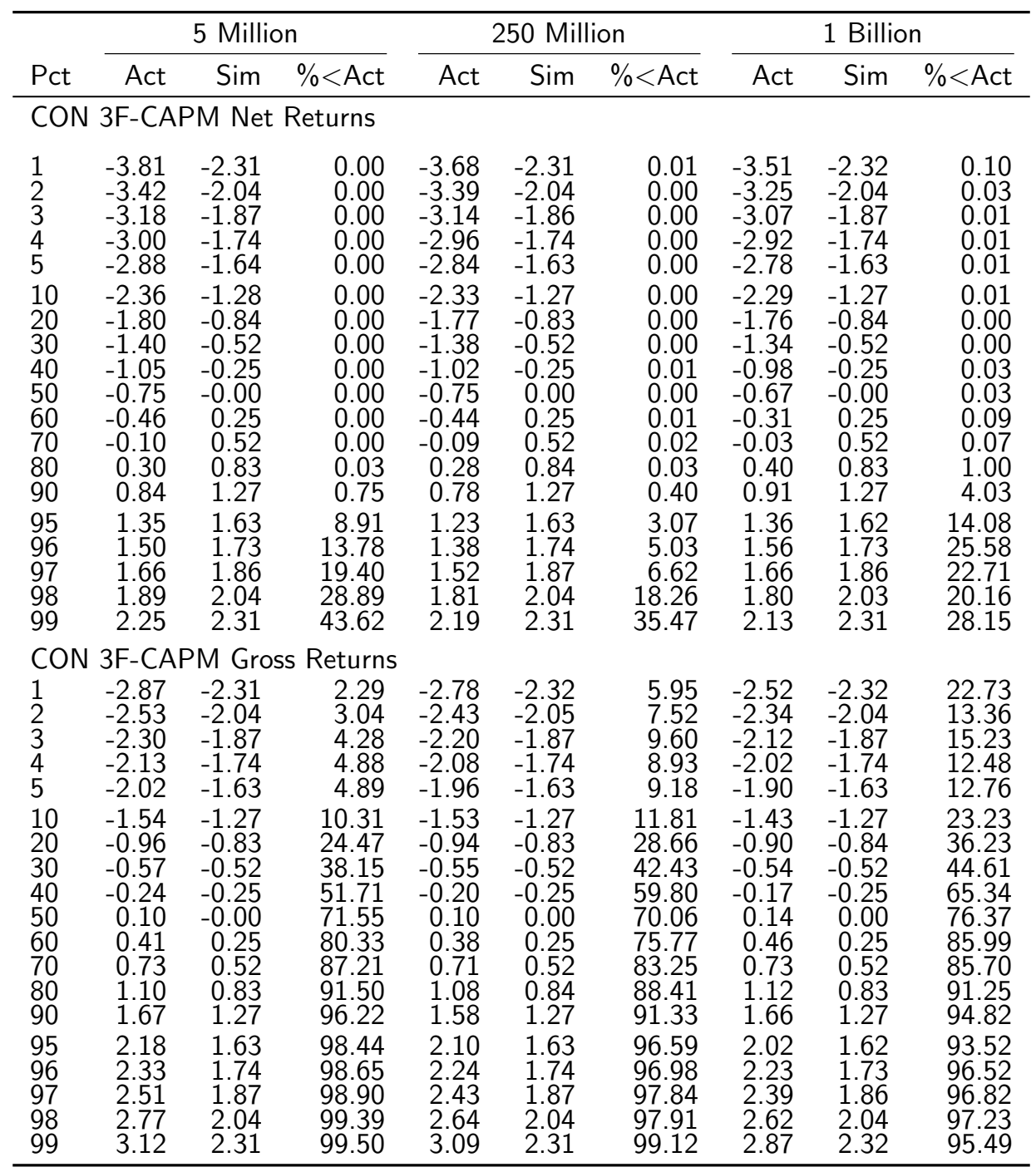

The smaller percentiles of the $t(\alpha)$ estimates tell us that poorly performing funds find themselves in the left tail because they consistently produce negative alpha and not from luck. In the right tail of this distribution, here too percentiles of $t(\alpha)$ estimates are smaller than the simulated percentiles (see column with header Sim). Here, the former percentiles (95th to 99th range from 1.35 to 2.25) are slightly smaller than the latter distribution's percentile (95th to 99th range from 1.63 to 2.31). As in the left tail, funds in the right tail were here due to good luck.

In general terms we find that funds with at least \$5 million AUM, over the years 1984 to the end of 2018, have not been able to generate positive alpha due to superior management but are there out of luck. Some funds also generate negative alpha either due to poor management of the fund or due to excessively large management fees. This contrast, to some extent, with the findings regarding fund 
performance that come from Table 3. Where, according to latter table, a small subset of funds were found to generate positive alpha consistently, which is in striking contrast to the findings on fund performance using the updated data. Regarding poor fund performance, the conclusions drawn from both tables agree. In this respect there is no conflict. There remains a subset of funds that produce negative alpha which cannot be attributed to bad luck.

\section{Additional tests for sub-samples and turbulent periods}

In order to examine our results further, as a final step in our analysis, we re-estimate the Ferson and Schadt (1996) model (cf. equation (1)) but allow only the market-risk to vary as was done in Section 6 for different sub-periods (namely the 1980s, 1990s, 2000s and 2010s), and for turbulent periods, such as the Dot Com crash and the 2007-2009 Financial crisis. This analysis is rather useful in terms of checking the stability of our findings towards the various evolutionary periods of US institutional investment industry, as well as towards exogenous factors that may have affected fund performance ${ }^{[23]}$.

Thus, table 6 lists the cross section distribution of $t(\alpha)$ estimates for the different decades (1980s, 1990s, 2000s, and 2010s). From this new set of results, we observe that on a gross returns basis (see Table 6, second panel), fund abnormal performance was very good during the mid to late $80 \mathrm{~s}$. Funds in the right tail were there due to skill, while funds in the left tail were there due to bad luck. During the following sub-period, 1900-1999, also on a gross return basis, funds in the extreme right tail were skilled, whereas funds in the left tail were unskilled. This conclusion applies unchanged to 2000-2009 but not for the 2010-2018 sub-period. For the latter period, fund abnormal performance deteriorates even further. Now funds only for the 98th and 99th percentiles had skill, while funds in the left tail were unskilled.

Much of what happened to funds on a gross return bases applies equally to net returns (see Table 6 , first panel). During the 1984-1989 period, funds in the right tail of this distribution were skilled and those in the left tail were unlucky. During the periods 1990-1999 and 2000-2009, fund abnormal performance deteriorated, as it did for gross returns. For a fund to be skilled, it now must be in the extreme right tail, whereas funds in the left tail were unskilled. During 2010-2018, fund abnormal performance deteriorated significantly, just as it did on a gross returns basis. Funds in the right tail were there because of luck, which contrasts with the extreme right tail based on gross returns; funds in the left tail were unskilled, as they were for gross returns.

Turning to the turbulent events of the early and late 2000s, Table 7 lists the cross section distribution of $t(\alpha)$ estimates for the entire sample and for the period of time without the Dot-come crash, as well as the Financial crisis, for both net and gross-returns. What can be observed from removal of fund returns corresponding to the Dot-com crash, is this produced slightly better fund abnormal performance due to somewhat larger percentiles in the right tail, for both net and gross returns. However, its effect on the percentiles in the left tail is more dramatic. Here, percentiles fell significantly compared to percentiles based on the whole sample (whole sample: 1st and 5th percentiles are -3.81 and -2.88 respectively; sub-sample that removes Dot-com returns: 1 st and 5 th percentiles are -4.11 and -3.14 respectively). In summary, the effect of the Dot-com crash on the distribution of abnormal performance, was to reduce marginally fund abnormal performance in the right tail, but to significantly increase abnormal fund performance in the left tail when compared to fund abnormal performance that preceded or followed this period.

Regarding the effect of the Financial Crisis, Table 7 (second panel), lists the cross-section distribution $t(\alpha)$ estimates for the entire sample as well as controlling for the Financial Crisis (i.e. removes the returns corresponding to the crisis). Comparing the two distributions, the sub-sample that controls for this crisis indicates a reduction in fund abnormal performance, as reflected by the percentiles in the extreme right

\footnotetext{
${ }^{23}$ We would like to thank an anonymous referee for making these suggestions, as they provide additional complementary insight to our overall analysis.
} 
tail (smaller percentiles for the sub-sample without the Financial Crisis) and abnormal performance much worse, as can be seen by the percentiles in the left tail (percentiles in the left tail are much smaller after removing returns of the Financial Crisis). To have this effect, fund abnormal performance would have been better than performance in the previous and subsequent periods, while some fund abnormal returns would not have been nearly as bad as the abnormal returns that occurred before and after this crisis ${ }^{\text {24. }}$. To summarize, funds performed (in terms of abnormal returns) better here than in the previous or subsequent periods.

Notwithstanding these two effects, the overall conclusions remain unchanged to those when returns corresponding to these two events are included. On a gross returns basis, funds, if in the right tail, are skilled, whereas funds in the left tail are unskilled. On a net return basis, funds, if located in the right tail, are there because of luck, while funds in the left tail are unskilled.

\footnotetext{
${ }^{24}$ Possible explanations to our result that managers performed slightly better during the financial crisis period could be their strategy of active investing. They can reallocate their portfolios to take advantages of the bearish market condition. For example, managers were able to purchase stocks at low prices. They also benefited from the quantitative easing or rescue packages from the central government. There is a rich literature dated back to the 1970s, like Fabozzi and Francis (1979), on whether mutual funds can take advantage of different market conditions. These empirical findings usually conclude funds did not decrease market betas in bearish market. However, our results suggest that mutual funds can implement active investing strategies that allow them to benefit from bearish market conditions like the global financial crisis as they learned over the decades and after dot-com crash. This could lead to the fact that mutual funds perform slightly better in the bearish market condition during the financial crisis than the pre- and post-crisis period.
} 
Table 6: Percentiles of Actual and Simulated $t(\alpha)$ Estimates in Subsample Periods Using Ferson \& Schadt (1996) Model (CON 3F-CAPM)

The table shows values of actual (Act) $t(\alpha)$ estimates at selected percentiles (Pct) of the distribution of $t(\alpha)$ estimates for net and gross returns. Sim is the average value of $t(\alpha)$ at the selected percentiles from the simulations. We bootstrap by resampling fund and factor returns jointly as a pair. It also shows the fractions of the 10,000 simulated $t(\alpha) s$ percentiles that are less than the averaged percentiles of $t(\alpha)$ estimates $(\%<\mathrm{Act})$. The four subsamples cover the periods: January 1984 to December 1989, January 1990 to December 1999, January 2000 to December 2009, and January 2010 to December 2018. Results are shown for the 3F-CAPM using Ferson \& Schadt (1996) Model using returns of the \$5 million AUM group.

\begin{tabular}{|c|c|c|c|c|c|c|c|c|c|c|c|c|}
\hline \multirow[b]{2}{*}{ Pct } & \multicolumn{3}{|c|}{$1984-1989$} & \multicolumn{3}{|c|}{ 1990-1999 } & \multicolumn{3}{|c|}{$2000-2009$} & \multicolumn{3}{|c|}{$2010-2018$} \\
\hline & Act & Sim & $\%<$ Act & Act & Sim & $\%<$ & Act & Sim & $\%<$ Act & Act & Sim & $\%<$ Act \\
\hline \multicolumn{13}{|c|}{ 3F-CAPM, Net Returns } \\
\hline \multirow[t]{2}{*}{$\begin{array}{l}1 \\
2 \\
3 \\
4 \\
5 \\
10 \\
20 \\
30 \\
40 \\
50 \\
60 \\
70 \\
80 \\
90 \\
95 \\
96 \\
97 \\
98 \\
99 \\
\end{array}$} & $\begin{array}{l}-2.85 \\
-2.54 \\
-2.30 \\
-2.14 \\
-2.01 \\
-1.54 \\
-0.98 \\
-0.49 \\
-0.05 \\
0.29 \\
0.72 \\
1.04 \\
1.51 \\
2.26 \\
2.89 \\
3.02 \\
3.31 \\
3.51 \\
3.85 \\
\end{array}$ & $\begin{array}{l}-2.25 \\
-2.01 \\
-1.86 \\
-1.74 \\
-1.62 \\
-1.27 \\
-0.83 \\
-0.52 \\
-0.24 \\
0.01 \\
0.27 \\
0.54 \\
0.86 \\
1.30 \\
1.66 \\
1.77 \\
1.89 \\
2.05 \\
2.29 \\
\end{array}$ & $\begin{array}{r}7.81 \\
8.40 \\
10.05 \\
10.72 \\
11.31 \\
15.94 \\
27.03 \\
52.69 \\
80.13 \\
89.69 \\
96.77 \\
96.69 \\
97.94 \\
99.24 \\
99.62 \\
99.57 \\
99.74 \\
99.78 \\
99.77\end{array}$ & $\begin{array}{r}-3.93 \\
-3.63 \\
-3.41 \\
-3.27 \\
-3.13 \\
-2.62 \\
-2.05 \\
-1.63 \\
-1.21 \\
-0.82 \\
-0.36 \\
0.14 \\
0.62 \\
1.31 \\
1.85 \\
2.03 \\
2.18 \\
2.49 \\
2.84 \\
\end{array}$ & $\begin{array}{r}-2.20 \\
-1.94 \\
-1.78 \\
-1.64 \\
-1.55 \\
-1.20 \\
-0.78 \\
-0.48 \\
-0.22 \\
0.02 \\
0.26 \\
0.52 \\
0.82 \\
1.23 \\
1.57 \\
1.67 \\
1.80 \\
1.96 \\
2.21 \\
\end{array}$ & $\begin{array}{r}0.02 \\
0.01 \\
0.01 \\
0.00 \\
0.00 \\
0.00 \\
0.00 \\
0.00 \\
0.00 \\
0.00 \\
0.04 \\
2.55 \\
19.29 \\
64.53 \\
85.21 \\
89.58 \\
90.08 \\
94.94 \\
95.78 \\
\end{array}$ & $\begin{array}{r}-3.17 \\
-2.87 \\
-2.66 \\
-2.40 \\
-2.28 \\
-1.75 \\
-1.19 \\
-0.82 \\
-0.43 \\
-0.14 \\
0.17 \\
0.46 \\
0.86 \\
1.39 \\
1.83 \\
1.99 \\
2.15 \\
2.32 \\
2.77 \\
\end{array}$ & $\begin{array}{l}-2.23 \\
-1.97 \\
-1.81 \\
-1.68 \\
-1.58 \\
-1.23 \\
-0.82 \\
-0.52 \\
-0.26 \\
-0.01 \\
0.23 \\
0.49 \\
0.79 \\
1.21 \\
1.56 \\
1.66 \\
1.79 \\
1.95 \\
2.21 \\
\end{array}$ & $\begin{array}{r}1.01 \\
0.91 \\
1.11 \\
1.96 \\
2.24 \\
4.96 \\
9.73 \\
13.41 \\
25.56 \\
31.64 \\
42.12 \\
47.85 \\
61.65 \\
74.26 \\
81.58 \\
85.12 \\
86.64 \\
86.66 \\
92.75 \\
\end{array}$ & $\begin{array}{r}-4.54 \\
-4.08 \\
-3.82 \\
-3.65 \\
-3.51 \\
-3.03 \\
-2.40 \\
-1.95 \\
-1.61 \\
-1.29 \\
-0.94 \\
-0.58 \\
0.19 \\
0.39 \\
0.81 \\
0.93 \\
1.10 \\
1.34 \\
1.64 \\
\end{array}$ & $\begin{array}{r}-2.23 \\
-1.97 \\
-1.81 \\
-1.69 \\
-1.58 \\
-1.24 \\
-0.81 \\
-0.50 \\
-0.24 \\
0.01 \\
0.26 \\
0.53 \\
0.83 \\
1.26 \\
1.60 \\
1.70 \\
1.82 \\
1.98 \\
2.24 \\
\end{array}$ & $\begin{array}{l}0.00 \\
0.00 \\
0.00 \\
0.00 \\
0.01 \\
0.00 \\
0.00 \\
0.00 \\
0.00 \\
0.00 \\
0.00 \\
0.00 \\
0.00 \\
0.00 \\
0.04 \\
0.06 \\
0.21 \\
1.08 \\
2.53 \\
\end{array}$ \\
\hline & \multicolumn{3}{|c|}{$1984-1989$} & \multicolumn{3}{|c|}{ 1990-1999 } & \multicolumn{3}{|c|}{$2000-2009$} & \multicolumn{3}{|c|}{$2010-2018$} \\
\hline Pct & Act & Sim & $\%<$ Act & Act & Sim & $\%<$ Act & Act & Sim & $\%<$ Act & Act & Sim & $\%<$ Act \\
\hline \multicolumn{13}{|c|}{ 3F-CAPM, Gross Returns } \\
\hline $\begin{array}{l}1 \\
2 \\
3 \\
4 \\
5 \\
10 \\
20 \\
30 \\
40 \\
50 \\
60 \\
70 \\
80 \\
90 \\
95 \\
96 \\
97 \\
98\end{array}$ & $\begin{array}{r}-2.57 \\
-2.04 \\
-1.84 \\
-1.78 \\
-1.60 \\
-0.98 \\
-0.45 \\
-0.04 \\
0.35 \\
0.74 \\
1.17 \\
1.48 \\
1.93 \\
2.70 \\
3.45 \\
3.60 \\
3.85 \\
4.13 \\
4.38\end{array}$ & $\begin{array}{l}-2.26 \\
-2.02 \\
-1.86 \\
-1.74 \\
-1.63 \\
-1.27 \\
-0.84 \\
-0.52 \\
-0.25 \\
0.01 \\
0.27 \\
0.54 \\
0.86 \\
1.30 \\
1.66 \\
1.77 \\
1.89 \\
2.05 \\
2.29\end{array}$ & $\begin{array}{l}20.66 \\
45.22 \\
49.69 \\
43.06 \\
51.36 \\
86.26 \\
95.22 \\
98.60 \\
99.60 \\
99.83 \\
99.95 \\
99.86 \\
99.88 \\
99.96 \\
99.99 \\
99.98 \\
99.98 \\
99.99 \\
99.98\end{array}$ & $\begin{array}{r}-3.12 \\
-2.97 \\
-2.73 \\
-2.59 \\
-2.50 \\
-2.00 \\
-1.42 \\
-0.99 \\
-0.62 \\
-0.18 \\
0.19 \\
0.66 \\
1.17 \\
1.79 \\
2.40 \\
2.49 \\
2.72 \\
2.95 \\
3.18\end{array}$ & $\begin{array}{r}-2.19 \\
-1.93 \\
-1.77 \\
-1.64 \\
-1.54 \\
-1.20 \\
-0.78 \\
-0.48 \\
-0.22 \\
0.02 \\
0.26 \\
0.52 \\
0.81 \\
1.23 \\
1.56 \\
1.66 \\
1.79 \\
1.95 \\
2.20\end{array}$ & $\begin{array}{r}0.89 \\
0.31 \\
0.33 \\
0.25 \\
0.13 \\
0.22 \\
0.30 \\
0.89 \\
2.32 \\
14.86 \\
36.68 \\
76.32 \\
94.31 \\
98.11 \\
99.64 \\
99.51 \\
99.72 \\
99.72 \\
99.39\end{array}$ & $\begin{array}{r}-2.50 \\
-2.15 \\
-1.99 \\
-1.82 \\
-1.67 \\
-1.16 \\
-0.55 \\
-0.20 \\
0.14 \\
0.45 \\
0.76 \\
1.10 \\
1.46 \\
2.01 \\
2.47 \\
2.57 \\
2.71 \\
2.92 \\
3.35\end{array}$ & $\begin{array}{r}-2.24 \\
-1.97 \\
-1.81 \\
-1.69 \\
-1.58 \\
-1.24 \\
-0.82 \\
-0.52 \\
-0.26 \\
-0.01 \\
0.23 \\
0.49 \\
0.80 \\
1.22 \\
1.56 \\
1.67 \\
1.79 \\
1.96 \\
2.22\end{array}$ & $\begin{array}{l}20.04 \\
25.73 \\
25.23 \\
29.43 \\
35.26 \\
58.49 \\
84.00 \\
88.64 \\
93.50 \\
95.67 \\
97.02 \\
97.76 \\
98.19 \\
98.67 \\
99.12 \\
99.05 \\
98.99 \\
99.02 \\
99.39\end{array}$ & $\begin{array}{r}-3.43 \\
-3.10 \\
-2.86 \\
-2.67 \\
-2.52 \\
-2.11 \\
-1.46 \\
-1.04 \\
-0.72 \\
-0.41 \\
-0.07 \\
0.28 \\
0.67 \\
1.27 \\
1.71 \\
1.84 \\
2.00 \\
2.25 \\
2.64\end{array}$ & $\begin{array}{r}-2.23 \\
-1.97 \\
-1.81 \\
-1.69 \\
-1.59 \\
-1.24 \\
-0.82 \\
-0.51 \\
-0.24 \\
0.01 \\
0.26 \\
0.52 \\
0.83 \\
1.25 \\
1.60 \\
1.69 \\
1.82 \\
1.98 \\
2.24\end{array}$ & $\begin{array}{r}0.53 \\
0.51 \\
0.67 \\
0.74 \\
0.83 \\
0.85 \\
2.05 \\
3.43 \\
4.10 \\
5.92 \\
10.83 \\
17.96 \\
29.93 \\
55.71 \\
67.40 \\
70.34 \\
73.90 \\
80.38 \\
87.66\end{array}$ \\
\hline
\end{tabular}


Table 7: Percentiles of Actual and Simulated $t(\alpha)$ Estimates in Subsample Periods Using Ferson \& Schadt (1996) Model (CON 3F-CAPM)

The table shows values of actual (Act) $t(\alpha)$ estimates at selected percentiles (Pct) of the distribution of $t(\alpha)$ estimates for net and gross returns. Sim is the average value of $t(\alpha)$ at the selected percentiles from the simulations. We bootstrap by resampling fund and factor returns jointly as a pair. It also shows the fractions of the 10,000 simulated $t(\alpha)$ s percentiles that are less than the averaged percentiles of $t(\alpha)$ estimates $(\%<$ Act $)$. The whole samples cover returns from January 1984 to December 31 2018, whereas the Subsample excludes fund returns corresponding to the Financial Crises (December 2007 to June 2009). Results are shown for the 3F-CAPM using the Ferson \& Schadt (1996) model estimated using returns of the $\$ 5$ million AUM group.

\begin{tabular}{|c|c|c|c|c|c|c|c|c|c|c|c|c|}
\hline \multirow[b]{4}{*}{ Pct } & \multicolumn{12}{|c|}{ Dot-com Crash } \\
\hline & \multicolumn{6}{|c|}{ 3F-CAPM, Net Returns } & \multicolumn{6}{|c|}{ 3F-CAPM, Gross Returns } \\
\hline & \multicolumn{3}{|c|}{ Whole sample } & \multicolumn{3}{|c|}{ Subsample } & \multicolumn{3}{|c|}{ Whole sample } & \multicolumn{3}{|c|}{ Subsample } \\
\hline & Act & Sim & $\%<$ Act & Act & Sim & $\%<\mathrm{Act}$ & Act & Sim & $\%<$ Act & Act & Sim & $\%<\mathrm{Act}$ \\
\hline $\begin{array}{l}1 \\
2 \\
3 \\
4 \\
5 \\
10 \\
20 \\
30 \\
40 \\
50 \\
60 \\
70 \\
80 \\
90 \\
95 \\
96 \\
97 \\
98 \\
99 \\
\end{array}$ & $\begin{array}{r}-3.81 \\
-3.42 \\
-3.18 \\
-3.00 \\
-2.88 \\
-2.36 \\
-1.80 \\
-1.40 \\
-1.05 \\
-0.75 \\
-0.46 \\
-0.10 \\
0.30 \\
0.84 \\
1.35 \\
1.50 \\
1.66 \\
1.89 \\
2.25 \\
\end{array}$ & $\begin{array}{l}-2.31 \\
-2.04 \\
-1.87 \\
-1.74 \\
-1.64 \\
-1.28 \\
-0.84 \\
-0.52 \\
-0.25 \\
-0.00 \\
0.25 \\
0.52 \\
0.83 \\
1.27 \\
1.63 \\
1.73 \\
1.86 \\
2.04 \\
2.31 \\
\end{array}$ & $\begin{array}{r}0.00 \\
0.00 \\
0.00 \\
0.00 \\
0.00 \\
0.00 \\
0.00 \\
0.00 \\
0.00 \\
0.00 \\
0.00 \\
0.00 \\
0.03 \\
0.75 \\
8.91 \\
13.78 \\
19.40 \\
28.89 \\
43.62 \\
\end{array}$ & $\begin{array}{r}-4.11 \\
-3.66 \\
-3.46 \\
-3.31 \\
-3.14 \\
-2.66 \\
-2.06 \\
-1.65 \\
-1.26 \\
-0.92 \\
-0.59 \\
-0.24 \\
0.20 \\
0.79 \\
1.34 \\
1.52 \\
1.71 \\
1.94 \\
2.32 \\
\end{array}$ & $\begin{array}{r}-2.30 \\
-2.02 \\
-1.85 \\
-1.72 \\
-1.62 \\
-1.26 \\
-0.82 \\
-0.51 \\
-0.24 \\
0.01 \\
0.25 \\
0.52 \\
0.83 \\
1.27 \\
1.63 \\
1.73 \\
1.86 \\
2.03 \\
2.31 \\
\end{array}$ & $\begin{array}{r}0.00 \\
0.00 \\
0.00 \\
0.00 \\
0.00 \\
0.00 \\
0.00 \\
0.00 \\
0.00 \\
0.00 \\
0.00 \\
0.00 \\
0.01 \\
0.16 \\
6.91 \\
15.10 \\
26.36 \\
36.24 \\
56.20 \\
\end{array}$ & $\begin{array}{r}-2.87 \\
-2.53 \\
-2.30 \\
-2.13 \\
-2.02 \\
-1.54 \\
-0.96 \\
-0.57 \\
-0.24 \\
0.10 \\
0.41 \\
0.73 \\
1.10 \\
1.67 \\
2.18 \\
2.33 \\
2.51 \\
2.77 \\
3.12 \\
\end{array}$ & $\begin{array}{l}-2.31 \\
-2.04 \\
-1.87 \\
-1.74 \\
-1.63 \\
-1.27 \\
-0.83 \\
-0.52 \\
-0.25 \\
-0.00 \\
0.25 \\
0.52 \\
0.83 \\
1.27 \\
1.63 \\
1.74 \\
1.87 \\
2.04 \\
2.31 \\
\end{array}$ & $\begin{array}{r}2.29 \\
3.04 \\
4.28 \\
4.88 \\
4.89 \\
10.31 \\
24.47 \\
38.15 \\
51.71 \\
71.55 \\
80.33 \\
87.21 \\
91.50 \\
96.22 \\
98.44 \\
98.65 \\
98.90 \\
99.39 \\
99.50 \\
\end{array}$ & $\begin{array}{r}-3.09 \\
-2.65 \\
-2.46 \\
-2.31 \\
-2.22 \\
-1.72 \\
-1.14 \\
-0.75 \\
-0.37 \\
-0.05 \\
0.28 \\
0.63 \\
1.03 \\
1.63 \\
2.17 \\
2.32 \\
2.52 \\
2.83 \\
3.11 \\
\end{array}$ & $\begin{array}{r}-2.29 \\
-2.02 \\
-1.85 \\
-1.72 \\
-1.61 \\
-1.25 \\
-0.82 \\
-0.51 \\
-0.24 \\
0.01 \\
0.26 \\
0.53 \\
0.84 \\
1.27 \\
1.63 \\
1.73 \\
1.86 \\
2.03 \\
2.31 \\
\end{array}$ & $\begin{array}{r}0.50 \\
1.04 \\
0.99 \\
0.98 \\
0.78 \\
1.63 \\
4.91 \\
8.99 \\
22.96 \\
36.24 \\
55.93 \\
72.70 \\
84.80 \\
95.42 \\
98.71 \\
98.99 \\
99.35 \\
99.67 \\
99.60 \\
\end{array}$ \\
\hline \multicolumn{13}{|c|}{ The Global Financial Crisis } \\
\hline & \multicolumn{6}{|c|}{ 3F-CAPM, Net Returns } & \multicolumn{6}{|c|}{ 3F-CAPM, Gross Returns } \\
\hline & \multicolumn{3}{|c|}{ Whole sample } & \multicolumn{3}{|c|}{ Subsample } & \multicolumn{3}{|c|}{ Whole sample } & \multicolumn{3}{|c|}{ Subsample } \\
\hline Pct & Act & Sim & $\%<$ Act & Act & Sim & $\%<$ Act & Act & Sim & $\%<$ Act & Act & Sim & $\%<$ Act \\
\hline $\begin{array}{l}1 \\
2 \\
3 \\
4 \\
5 \\
10 \\
20 \\
30 \\
40 \\
50 \\
60 \\
70 \\
80 \\
90 \\
95 \\
96 \\
97 \\
98 \\
99\end{array}$ & $\begin{array}{r}-3.81 \\
-3.42 \\
-3.18 \\
-3.00 \\
-2.88 \\
-2.36 \\
-1.80 \\
-1.40 \\
-1.05 \\
-0.75 \\
-0.46 \\
-0.10 \\
0.30 \\
0.84 \\
1.35 \\
1.50 \\
1.66 \\
1.89 \\
2.25\end{array}$ & $\begin{array}{l}-2.31 \\
-2.04 \\
-1.87 \\
-1.74 \\
-1.64 \\
-1.28 \\
-0.84 \\
-0.52 \\
-0.25 \\
-0.00 \\
0.25 \\
0.52 \\
0.83 \\
1.27 \\
1.63 \\
1.73 \\
1.86 \\
2.04 \\
2.31\end{array}$ & $\begin{array}{r}0.00 \\
0.00 \\
0.00 \\
0.00 \\
0.00 \\
0.00 \\
0.00 \\
0.00 \\
0.00 \\
0.00 \\
0.00 \\
0.00 \\
0.03 \\
0.75 \\
8.91 \\
13.78 \\
19.40 \\
28.89 \\
43.62\end{array}$ & $\begin{array}{r}-4.08 \\
-3.72 \\
-3.50 \\
-3.27 \\
-3.14 \\
-2.68 \\
-2.04 \\
-1.60 \\
-1.21 \\
-0.88 \\
-0.55 \\
-0.20 \\
0.24 \\
0.80 \\
1.29 \\
1.42 \\
1.63 \\
1.85 \\
2.14\end{array}$ & $\begin{array}{r}-2.31 \\
-2.04 \\
-1.87 \\
-1.74 \\
-1.63 \\
-1.27 \\
-0.83 \\
-0.52 \\
-0.25 \\
0.00 \\
0.25 \\
0.52 \\
0.84 \\
1.27 \\
1.64 \\
1.74 \\
1.87 \\
2.04 \\
2.31\end{array}$ & $\begin{array}{r}0.00 \\
0.00 \\
0.00 \\
0.00 \\
0.00 \\
0.00 \\
0.00 \\
0.00 \\
0.00 \\
0.00 \\
0.00 \\
0.00 \\
0.00 \\
0.42 \\
4.50 \\
6.31 \\
14.13 \\
21.83 \\
26.28\end{array}$ & $\begin{array}{r}-2.87 \\
-2.53 \\
-2.30 \\
-2.13 \\
-2.02 \\
-1.54 \\
-0.96 \\
-0.57 \\
-0.24 \\
0.10 \\
0.41 \\
0.73 \\
1.10 \\
1.67 \\
2.18 \\
2.33 \\
2.51 \\
2.77 \\
3.12\end{array}$ & $\begin{array}{l}-2.31 \\
-2.04 \\
-1.87 \\
-1.74 \\
-1.63 \\
-1.27 \\
-0.83 \\
-0.52 \\
-0.25 \\
-0.00 \\
0.25 \\
0.52 \\
0.83 \\
1.27 \\
1.63 \\
1.74 \\
1.87 \\
2.04 \\
2.31\end{array}$ & $\begin{array}{r}2.29 \\
3.04 \\
4.28 \\
4.88 \\
4.89 \\
10.31 \\
24.47 \\
38.15 \\
51.71 \\
71.55 \\
80.33 \\
87.21 \\
91.50 \\
96.22 \\
98.44 \\
98.65 \\
98.90 \\
99.39 \\
99.50\end{array}$ & $\begin{array}{r}-3.07 \\
-2.77 \\
-2.55 \\
-2.38 \\
-2.24 \\
-1.76 \\
-1.18 \\
-0.76 \\
-0.40 \\
-0.05 \\
0.28 \\
0.62 \\
1.01 \\
1.61 \\
2.08 \\
2.21 \\
2.38 \\
2.59 \\
2.95\end{array}$ & $\begin{array}{r}-2.31 \\
-2.04 \\
-1.87 \\
-1.74 \\
-1.63 \\
-1.27 \\
-0.83 \\
-0.52 \\
-0.25 \\
0.00 \\
0.26 \\
0.52 \\
0.84 \\
1.28 \\
1.64 \\
1.74 \\
1.87 \\
2.04 \\
2.32\end{array}$ & $\begin{array}{r}0.50 \\
1.04 \\
0.99 \\
0.98 \\
0.78 \\
1.63 \\
4.91 \\
8.99 \\
22.96 \\
36.24 \\
55.93 \\
72.70 \\
84.80 \\
95.42 \\
98.71 \\
98.99 \\
99.35 \\
99.67 \\
99.60\end{array}$ \\
\hline
\end{tabular}




\section{Changes to financial regulation and compensation practices for mutual funds}

The empirical results and the relevant discussion of this paper are quite topical. A recent CNBC online article headline states Active fund managers trail the $S \& P 500$ for the ninth year in a row in triumph for indexing ${ }^{\sqrt{25}}$. The article provides online pronouncement of the poor performance of U.S. mutual funds based on the S\&P Dow Jones Indices annual report. The report finds that during last year, $64.9 \%$ of large-cap mutual funds reported lower earnings than returns on the S\&P index. More importantly this result is repeated over the last nine years. Regarding performance over the last 10 years, $85 \%$ of large-cap funds underperformed the S\&P index, and after 15 years almost $92 \%$ of them trailed the index in annual returns. From all this, one is left to conclude that funds may perform well for one or two years but performance does not persist after that.

The above is telling story of the poor performance of actively managed U.S. mutual funds over the last 16 years. Results from our estimations and simulations detailed in Table 5 support the statements made in this article. It also sheds some light on it as well. When performance measured by gross returns, percentiles of the distribution of $t(\alpha)$ estimates are well above those of the simulated percentiles, particularly in the right tail of this distributions. $\%<$ Act show that a large proportion of simulated $t(\alpha) \mathrm{s}$ are smaller than percentiles of $t(\alpha)$ estimates. However, when measured on a net returns basis, the simulations paint a different picture of fund performance. Now a large proportion of the simulated percentiles (see column header $\%<$ Act) are larger than those of the estimated $t(\alpha) .91 \%$ of the simulated percentiles are larger than the $95 \%$ percentile of the estimated $t(\alpha)$; by the 99th percentile of the latter distribution, this falls to $66 \%$. Performance falls substantially when measured on a net returns basis. As the only missing item in gross returns are management expenses, the poor performance in the right tail of the $t(\alpha)$ estimates can be attributed to them. However, in the left tail of the $t(\alpha)$ estimates, poor performance is due more to bad management of the fund.

Much of the poor performance, for those funds that exist in the right tail of the cross section distribution, is due to excessive management fees that management demands in returns for its services. In the end, these fees reduce the returns of a fund. Possible ways to avoid this problem are difficult to find because mutual funds have a dispersed set of beneficiaries and no large shareholders who can monitor the fund. To overcome a lack of monitoring, one possible solution would be to appoint an outside agent to represent beneficiaries. Monitoring by one agent allows for more input in decisions regarding management fees as well as on other matters. One possibility would be to negotiate lower management fees as well as push for reductions in load fees that are often charged by funds to beneficiaries who exit the fund. This offers a way for mutual fund investors to receive returns that would normally pass to managers in the form of fees.

A second problem comes from existing compensation practices employed in the mutual fund industry. Current practices do not align managerial incentives with interests of the beneficiaries because managers are paid as a function of assets under management rather than an incentive based compensation: i.e. one based on capital appreciation of a fund. ${ }^{\sqrt{6}}$ The former compensation practice provides incentives for a manager to expand their fund to an extent where fund size is no longer optimal. Inefficiencies associated with operation of a fund that is too large reduces returns that can be paid to the beneficiaries. This is likely to contribute to poor performance of fund returns. Therefore contributing to the large left tail of the $t(\alpha)$ estimates we see in our estimations. Changing the incentives management receive to one based on appreciation of the fund rather than based on its size (large assets under management) would lead to efficient fund size. Financial regulators should require funds to employ compensation practices based on

\footnotetext{
${ }^{25}$ Bob Pisani (March 14 2019) Active fund managers trail the S\&P500 for the ninth year in a triumph for indexing, https://www.cnbc.com/2019/03/15/active-fund-managers-trail-the-sp-500-for-the-ninth-year-in-a-row-in-triumph-forindexing.html

${ }^{26}$ See page 41 of Tirole $(2006)$ for a brief discussion of the difficulties with monitoring management and remuneration practices of the mutual fund industry.
} 
appreciating a fund's value.

\section{Conclusions}

Our re-appraisal of Fama and French (2010) repeats the analysis they perform but replaces unconditional versions of the CAPM with conditional versions based on Ferson and Schadt (1996). Using U.S. mutual fund returns data for the period January 1984 to September 2006, as used by F\&F in their paper, we show that the latter models have significant effects on estimation of percentiles of the cross section of the performance distribution but has only slight effects on the simulated versions.

On a net returns basis, our estimate of the cross section distribution of $t(\alpha)$ estimates has much larger percentiles in the right tail of this distribution but only marginal effect on the simulated $t(\alpha)$. Throughout the simulations, funds are forced to have zero alpha. Hence the much larger percentiles of our distribution of $t(\alpha)$ estimates cannot be due to luck. Now funds have an ability to generate positive alpha which is in contrast to the findings of $F \& F$ who find funds in the right tail of this distribution are there only due to good luck. Regarding the extreme left tail of $t(\alpha)$ estimates, use of the conditional CAPM of Ferson and Schadt (1996) has little effect on the percentiles. They remain very small and much smaller than the simulated versions. Hence, our estimations and simulations do not overturn the results of $F \& F$ in the left tail. Funds located in the left extreme left tail are there because of poor performance and not from bad luck.

From a gross returns perspective, percentiles of $t(\alpha)$ estimates in the right tail are larger than those estimated by F\&F. In the left tail of this distribution, the percentiles are slightly larger than those estimated by F\&F. Hence our conclusions are similar to theirs. Funds located in the left-tail are located there because they are truly negative alpha funds, while funds in the extreme right-tail are truly positive alpha. To see the evolution of fund performance since 2006, the upper limit of the data used by F\&F, we update results to December $31^{\text {st }}$ 2018. Here, we find that fund performance has deteriorated so much so that our conclusions regarding fund performance returns to the same conclusions of $F \& F$. Fund performance has been so poor over these additional years that funds located in the extreme right tail are there due to good luck: they cannot generate positive alpha. Funds located in the extreme left tail are there, not due do bad luck, but because they generate negative alpha.

One important aspect is what happens to actively managed funds when the fees they charge decline. According to the Investment-Company-Institute (2019) Fact Book, expense ratios of actively managed funds fell from 2003 onwards with a slight rise in 2008-2009 period. Fund data used by Fama and French (2010) includes data from 2003 to September 2006. This reduction in fees would be absent from much of their data and therefore it would not have had much of an effect on the estimated $t(\alpha) \mathrm{s}$. The updated data set used in this paper includes the period 2003 to December 2018, which includes net returns calculated from the lower expense ratios. Falling expense ratio should have moved more funds to the right tail of the performance distribution and produced a larger right tail. This however did not happen. According to our results, funds in the right tail, were there out of luck and not due to skill. Funds in the left tail were there because they were unskilled, which is the same conclusion reached by Fama and French (2010).

One possible explanation for the large number of underperforming funds is due to the herding behaviour of mutual fund managers in their stock selection (cf. Jaing and Verardo (2018) for a detailed analysis of herding behavior of fund managers). This is particularly valid for the group of unskilled founds in the left tail of the cross-section distribution. To support this finding Jaing and Verardo (2018) find evidence that herding funds underperform anti-herding funds by $2.28 \%$, before and after expenses. Underperformance remains even after controlling for different factors such as market risk premium, size, 
value, momentum and liquidity. Depending on the factor, it can range from $1.68 \%$ to $2.52 \%$. Controlling for time-varying loadings, as in Ferson and Schadt (1996), the gap is estimated at $2.04 \%$. According to the authors, herding is associated with older funds that do not trade as much as anti-herding funds. They also test whether herding funds underperformance is due to bad luck, while anti-herding outperformance is due to luck using predictive panel regressions. They conclude that the performance gap (difference in anti-herding funds and herding funds' returns) persists up to 12 months, then tappers off but remains statistically and economically significant.

Our policy advice is two fold and offers ways to affect both ends of the performance distribution. One suggestion comes from the difference in performance when returns are measured net and gross. Lack of monitoring by a dispersed set of beneficiaries leaves no one investor with incentive to monitor managers to ensure fees are not excessive. Due to lack of monitoring, those funds in the extreme right tail of the performance distribution extract the excess returns which could have been returned to investors. Better design of the monitoring structure, which allows investors more input on the fees charged by management, should prevent this from occurring. Funds in the left tail this distribution, are there because of compensation practices employed by this industry. Current practice is for managers to be rewarded on the size of the assets under management (AUM) rather than a fund's capital appreciation. The effects of the latter practice is for funds to become inefficiently large which increases their marginal cost. Regulation requiring managers to be rewarded on a fund's capital appreciation should prevent funds from becoming inefficiently large due to asset purchases alone.

\section{Appendix A Constructing a survivor-bias-free dataset consisting of actively man- aged U.S. equity mutual mutual funds}

This appendix is arranged as follows: Section A.1 explains how to identify US equity mutual funds; Section A.2 details how to exclude passively managed funds; Section A.3 performs some check on how passively managed funds are determined; Section A.4 describes how mutual funds returns are selected; Section $A .5$ constructs a variable containing information on the different share classes a fund may issue; and Section A.6 creates fund net returns by aggregating value weighted share classes, then categorises funds into three investment styles and then generates gross fund returns.

\section{A.1 Selecting US equity mutual funds}

F\&F use data on mutual funds investing primarily in U.S. equity. Other funds, such as mortgagebacked, balanced, international, global, municipal, bond, money market and funds that invest in precious metals, are excluded from their data. To do this requires identification of a fund's style. Four objective codes in the CRSP fund data allow one to identify US equity mutual funds. Two important ones are weisenberger, which is imprecise (see French (2008)), and strategic insights, which is the most precise (see French (2008)). An additional variable, CRSP policy, is also used but not to the extent of the first two variables. In addition to these, F\&F use two variables more recently introduced to the CRSP fund data: Lipper and CRSP objective codes.

We select US equity mutual funds as long as one of the five variables listed above are not missing and meet the following two conditions:

1. A fund observation must be classified into one of the categories listed in Table 8 of the style/objective codes; 
Table 8: Styles or objectives that are classified as US equity mutual funds

\begin{tabular}{|c|c|}
\hline $\begin{array}{l}\text { Weisenberger } \\
(\text { wbrger_obj_cd })\end{array}$ & G, GCI, IEQ, LTG, MCG, SCG \\
\hline $\begin{array}{l}\text { Strategic insight objective codes } \\
\left(s i_{-} o b j_{-} c d\right)\end{array}$ & AGG, GMC, GRI, GRO, ING, SCG \\
\hline $\begin{array}{ll}\text { Lipper objective } & \text { codes } \\
(\text { lipper_obj_cd }) & \\
\end{array}$ & $\mathrm{CA}, \mathrm{EI}, \mathrm{G}, \mathrm{GI}, \mathrm{MC}$ \\
\hline CRSP style codes ( $\left.c r s p_{-} o b j_{-} c d\right)$ & $\begin{array}{l}\text { all that begin with ED or EDC or EDY, exclude } \\
\text { EDYH, EDYS }\end{array}$ \\
\hline Policy codes (policy) & CS, Flex, I-S, \\
\hline
\end{tabular}

2. We exclude any funds that are declared as non-US or non-equity by the Strategic Insight codes.

The variable per_com lists the percentage of a fund's assets invested in common stocks. Evans (2010) requires funds to have at least $90 \%$ of their assets held as equity according to the variable per_com. Kacperczyk et al. (2008) exclude funds that invest less than $80 \%$ or more than $100 \%$ of their assets in common stocks. Because this variable has missing values for a large number of fund observations, to avoid losing too many observations, we follow Kosowski et al. (2006) and include funds when its value is greater than $50 \%$.

\section{A.2 Excluding passively managed funds}

Section A.1 discusses how to reduce the set of mutual funds to those mainly investing in US equity. Among these funds part of them are comprised of index funds and ETFs (Exchange-traded funds). CRSP provides a variable named index_fund_flag to identify index funds, with character " $D$ " representing pure index fund, character " $E$ " representing enhanced index funds and character " $B$ " representing index-based funds. Another variable named et_flag identifies a fund as ETF or ETN (Exchange Traded Notes). These four types of funds need to be exclude from the data. However, these two variables are only available from the year 2003 and their values are often missing. Therefore, we select actively managed funds based on occurrences of key words in a fund names.

To do this, use the CRSP variable fund_name to scan for the following key words listed in Table 9 .

Table 9

\begin{tabular}{l|l|l|l|l}
\hline index & indx & idx & s\& $p$ & schwab 1000 \\
\hline nasdaq-100 & dow & jones & etf & ishare \\
\hline profound & russell & proshare & powershare & viper \\
\hline spider & spdr & wilshare & etn & \\
\hline exchange traded & exchange-traded & \\
\hline
\end{tabular}

If the variable fund_name contains any of the words listed in Table 9, as well as any of those given in Table 10, it is labelled as an Enhanced index fund.

Table 10

\begin{tabular}{l|l|l|l}
\hline hedge & manage & enhance & plus \\
\hline
\end{tabular}

To identify a Target-date fund the variable fund_name is scanned for the key words listed in Table 11$]$ and these key words must not contain "russell 2000", since "2000" is in Table 11 ${ }^{27}$.

\footnotetext{
${ }^{27}$ Funds that have russell 2000 in their fund name may mimick performance of the Russell 2000 index.
} 
Table 11

\begin{tabular}{l|l|l|l|l|l}
\hline 1970 & 1975 & 1980 & 1985 & 1990 & 1995 \\
\hline 2000 & 2005 & 2010 & 2015 & 2020 & 2025 \\
\hline 2030 & 2035 & 2040 & 2045 & 2050 & 2055 \\
\hline 2060 & target & lifestyle & & & \\
\hline
\end{tabular}

A leveraged index fund is identified if the fund contains at least one word from Table 12 but does not contain any word from Table 13 .

Table 12

\begin{tabular}{l|l|l|l|l|l}
\hline inverse & short & ultra & $1.25 x$ & $1.5 x$ & $2 x$ \\
\hline $2.5 x$ & $3 x$ & $4 x$ & $5 x$ & $6 x$ & $7 x$ \\
\hline $8 x$ & $9 x$ & $0 x$ & & & \\
\hline
\end{tabular}

Any fund found to have some of the key words given in Table 12 is likely to be a leveraged index fund. However, if a fund contains any of the key words in Table [13, it is not a leveraged index fund even if it has some of words in Table 12:

Table 13

\begin{tabular}{l|l|l|l|l|l}
\hline short term & short tm & short bond & short bnd & short bd & lg short \\
\hline long/short & long-short & long short & & & \\
\hline
\end{tabular}

If the fund is not labeled as one of the above four types, then we label that fund as actively managed.

To check the above classification method, we also screen funds based on their self-declared investment objectives (styles). When a funds has a missing investment style, it is common practice for studies to replace missing values with the previous non-missing value. For example, Barras et al. (2010) carries forward the prior non-missing objective(style) if an investment objective is missing. In this situation, funds are selected based on a complete self-declared investment styles. However, funds can change their investment style. According to our findings, there are 1835 fund-share classes in our sample that changed their investment styles during their life, accounting for around $9 \%$ of our entire equity share class dataset. Therefore, we only include a fund in a particular year if we are certain it is a U.S. equity fund for that year, i.e. the fund should have self-declared investment style indicating it invests primarily in US common stocks at the fiscal year end.

\section{A.3 Checks of assigned fund objective}

At one time or another, a few fund's observations may be assigned a different type. For example, a fund's observations my be labeled as one type but at some other time it may be labeled as another type. After all fund year-month observations are given a type, the type assigned is cross checked with the CRSP variable index_fund_flag which is the style assigned by CRSP. In a few cases, it is noticed that fund observations

1. are not labeled as ordinary index funds by our key words but are suggested to be index funds by the CRSP variable index_fund_flag with character "D";

2. are not labeled as enhanced index funds by our key words but are labelled as an enhanced index funds by the variable index_fund_flag with character "E";

3. are not labeled as either index or enhanced index funds by our key words but are labelled as an index-based funds by the variable index_fund_flag with character "B"; 
4. are not labeled as index funds by our key words but are labelled as an ETFs by the variable et_flag with character "F";

5. are not labeled as index funds by our key words but are labelled as an ETNs by the variable et_flag with character " $\mathrm{N}$ ";

6. are labeled as an ordinary index fund by our key words but are labelled as a non-index funds by the variable index_fund_flag with null character.

For those funds identified according to our classification explained above, we manually confirm its classification as well as calculate correlations between their historical monthly returns with returns of those of target stock indices. If a correlation of at least $99 \%$ is found, then we consider the fund to be an index fund and exclude it from our sample. To carry out this check, one must use fund returns, which requires a merge of the fund characteristic variables, i.e. their fund objective as determined above, with fund returns, as selected according to Section A.4. After these checks, several funds are known to be misspecified as index funds by our standards and are added back into our sample. These funds have the key word "russell" or "dow" or "jones". However, they are funds from "Russell Investment Company" or "Endowments Trust Company" or "Badson Shadow Stock Fund" or "Jones Villalta Opportunity Fund" which are in fact actively managed. Others funds with a correlation of at least $99 \%$ with a target stock index are identified as index funds by our standards but are in fact passively managed.

\section{A.4 Selecting mutual fund returns}

We use the Monthly Returns dataset here to obtain return histories of each fund, i.e. fund data for which there corresponds a valid return for that year, month and share class of a fund. Following French (2008), we select mutual fund share classes as long as they are known to be U.S. equity for a specific year. For those share classes for which CRSP has only quarterly information on investment styles, we use monthly returns observations if we are certain they are U.S. equity by the end of that quarter. For example, if a share class has an investment style for the first two quarters of a certain year that indicate it is US equity, then only returns for the first six months are used in our sample since we are uncertain about its investment style for the next two quarters of that year. A fund's month-year observation is also removed from its returns history when the corresponding return is missing as well as the following month's return because CRSP fills this with the cumulated return since the last non-missing Net Asset Value (NAV) ${ }^{28}$.

\section{A.5 Shareclasses and Portfolios}

Since performance is measured at the fund level, we need to combine returns of different share classes of a single fund to arrive at a fund's weighted monthly return. A new portfolio code called calc_portcode is assigned to different share classes of a fund. This variable should be similar to crsp_portno, but it uniquely identifies a portfolio, i.e a single fund, not a single share class of a fund. The name of a mutual fund observation in CRSP usually has two segments. The first segment contains the name of the actual fund, while the second segment contains the name of the specific share class, and these two segment are often seperated by the symbol ": " or "/". Generally, different share classes of the same fund should have identical names in their first segment. So we can build an algorithm to group together different share classes based on this first segment of their names. Specifically, the following steps are followed to assign the portfolio codes to subclasses:

\footnotetext{
${ }^{28}$ According to Center for Research in Security Prices (2014), on page 14 section of "Notes about returns ", monthly returns values are calculated as a change in NAV including reinvested dividends from one period to the next. Therefore, if there is a missing NAV, both the return for that month and the following-month return should be deleted.
} 
1. Delete observations with missing fund names.

2. Modify the share class name so that for the same share class it has only one name throughout its entire return history. We keep the most recent share class name.

3. Compress the names to remove the spaces between two letters and capitalise the names.

4. Extract the first segment of the observation's names out of the whole name so that the second segment of the name which contains the share class information is removed and only the part containing the name of the actual fund remains. This step can be done based on the fact that the two segments of names are often seperated by the character "; " or "/" in CRSP.

5. For each fund, find out if the fund has been renamed. If so, we change the old name to the most recent updated name. Repeat this process until there is no name discrepancies remaining within a single fund.

6. We use the "Levenshtein edit distance" to measure the distance between two strings (names) and compare it with a predefined cutoff (cutoff $=2$ ) to identify similar fund names to avoid name typos created by CRSP.

7. Finally, we check and make sure that the portfolio code we assign is not different within the same share class.

After the portfolio codes are assigned to all the subclasses, we proceed to check the accuracy of the newly created calc_portcode according to crsp_portno. crsp_portno exists in the original database as a portfolio identifier for a single fund that has multiple shareclasses. Unfortunately, the variable is missing for most funds, and that is why we need to construct our own portfolio identifier to merge different share classes of a single fund into one portfolio. However, we can still use those funds that have crsp_portno available to check if our portfolio identifier calc_portcode correctly assigns a unique code to a single fund portfolio, i.e. for those funds have non-missing crsp_portno, variables crsp_portno and calc_portcode should simultaneously identify the same fund portfolio. In other words, there should be no cases where the same crsp_portno is assigned to more than one calc_portcode. Finally, we manually check funds with more than 6 shareclasses to make sure that the correct portfolio codes are assigned.

\section{A.6 Fund style, value weighted net and gross returns}

Monthly returns for a single fund are calculated by weighting the net return of its component share classes by their beginning-of-month total net asset values (TNA). After share classes are assigned portfolio codes, monthly returns are weighted by their total net asset values (TNA) of that share class at the beginning of that month and are merged into a single fund. Before this can be done, if missing values are found for TNA they are replaced with the average of the non-missing before and after TNAs ${ }^{29}$.

Because expense ratios are only available on a yearly basis, monthly gross returns are obtained by adding $1 / 12^{\text {th }}$ of the yearly fund expense ratio to monthly net returns. Expense ratios can be missing for some funds in certain fiscal years. When a fund's expense ratio is missing, it is assumed to be the same as other actively managed funds with similar assets under management (AUM). Similar funds are defined as funds with the same investment style category and similar AUM. We assign three catefories of investment styles to funds in our sample according to Barras et al. (2010): income and growth funds, growth funds, and aggressive growth funds.

To be specific, we use style or objective codes to classify funds according to the following standards given in Table 14:

\footnotetext{
${ }^{29}$ In CRSP, there are some TNA observation values shown as "-99" in the database and are in fact missing values. We treat them as missing observations.
} 
Table 14: Investment styles or objectives to classify fund types

\begin{tabular}{|c|c|c|c|}
\hline & Growth \& income & Growth & $\begin{array}{l}\text { Aggressive } \\
\text { growth }\end{array}$ \\
\hline CRSP style codes ( $\left.c r s p_{-} o b j_{c} c d\right)$ & EDYB, EDYI & EDYG & \\
\hline $\begin{array}{l}\text { Weisenberger objective codes } \\
(\text { wbrger_obj_cd })\end{array}$ & $\mathrm{GCl}, \mathrm{IEQ}$ & LTG, SCG & MCG \\
\hline $\begin{array}{l}\text { Strategic insight objective codes } \\
\left(s i_{-} o b j_{-} c d\right)\end{array}$ & GRI, ING & GRO & AGG \\
\hline $\begin{array}{ll}\text { Lipper_objective } & \text { codes } \\
\text { (lipper_obj_cd) } & \end{array}$ & $\mathrm{Gl}, \mathrm{El}$ & $\mathrm{G}, \mathrm{CA}$ & \\
\hline Lipper class codes (lipper_class) & $\begin{array}{l}\text { EIEI, LCVE, MCVE, } \\
\text { MLVE, SCVE }\end{array}$ & $\begin{array}{l}\text { G, LCGE, MCGE, } \\
\text { MLGE, SCGE }\end{array}$ & \\
\hline
\end{tabular}

Fund names are also used to assist in this assignment because a fund's name can contain key words that indicate a fund's investment style. We use the key words in Table 15 to identify growth \& income funds:

Table 15: key words to identify growth \& income funds

\begin{tabular}{l|l|l}
\hline growth and income & growth \& income & income \& growth \\
\hline growth with income & income & value \\
\hline income and growth & income with growth & val \\
\hline
\end{tabular}

The key words listed in Table 16 are used to identify growth funds:

Table 16: key words to identify growth funds

\begin{tabular}{l|l|l|l|l}
\hline growth & $\begin{array}{l}\text { capital apprecia- } \\
\text { tion }\end{array}$ & appreciation & capital apprec & grth \\
\hline
\end{tabular}

Generally, any funds that have these key words in their names are very likey to be growth funds. However, there are exceptions. We put together another list of key words in Table 17 to refute a fund as a growth fund:

Table 17: key words to refute a fund as growth fund

\begin{tabular}{l|l|l|l}
\hline aggressive growth & aggressive & aggress growth & growth and income \\
\hline growth \& income & income and growth & income \& growth & growth with income \\
\hline income with growth & value & income & \\
\hline
\end{tabular}

Finally, we use the following key words in Table 18 to identify aggressive growth funds:

Table 18: key words to identify aggressive growth funds

\begin{tabular}{l|l|l|l}
\hline aggressive growth & aggressive & aggress growth & aggr growth \\
\hline
\end{tabular}

Once the above is completed, we create the new variable fund_style which indicates investment style of the funds in our sample. If a fund style is missing or cannot be identified using either style codes or fund name, it is labeled as missing. For funds with missing expense ratios, we fill in those missing expense ratios with non-missing expense ratios from funds with the same investment styles and similar AUM. 


\section{Appendix B Robustness of Fama and French (2010) to 16 months}

Table 19 details our estimates of the cross-section distribution of $t(\alpha)$ based on the 3F-CAPM now with the requirement that funds have at least sixteen months of returns data, the other conditions specified Section $\Omega$ remain the same. Requiring funds to have sixteen months of returns history rather than eight months has minor effect on the percentiles of this distribution, as can be seen from the table below. For example, based on net returns, the 99th percentile recorded below is 2.37 (column Act) but 2.48 (column Act) in Table $\square$, the later is larger by 0.11 . The corresponding percentiles for the simulated distributions are 2.36 (column Sim from Table 19) and 2.42 (column Sim from Table 2), with the later percentile larger than the former by 0.06 . Turning to the difference between the first percentiles, they are, respectively, $0.11(-4.00-(-3.89)=0.11)$ and $0.6(-2.36-(-2.33)=0.06)$. Summarising differences between the 2 nd to 98 th percentiles for the two distributions, they are almost the same. As a consequence of this observation, we conclude this slight change did not introduce survivor bias to our data, and therefore, it has no effect on results reported in Tables 3-5. 
Table 19: Replication of Table III of Fama and French (2010) using unconditional 3F-CAPM requiring funds to have $\mathbf{1 6}$ months of returns: Percentiles of Actual and Simulated $t(\alpha)$ Estimates: 1984 to 2006

This table shows values of actual (Act) $t(\alpha)$ estimates at selected percentiles (Pct) of the distribution of $t(\alpha)$ estimates for net and gross returns. Sim is the average value of $t(\alpha)$ at the selected percentiles from the simulations. We bootstrap by resampling fund and factor returns as a pair. It also shows the fractions of the 10,000 simulated $t(\alpha)$ s that are less than the averaged percentiles of $t(\alpha)$ estimates $(\%<$ Act). The sample covers the period from January 1984 to September 2006, including funds that have at least 16 months of return history. Results are shown for the 3F-CAPM, for the $\$ 5$ million, $\$ 250$ million, and $\$ 1$ billion AUM groups. There are 2961 funds in the $\$ 5$ million group, 1338 funds in the $\$ 250$ million group, and 609 funds in the $\$ 1$ billion group.

\begin{tabular}{|c|c|c|c|c|c|c|c|c|c|}
\hline \multirow[b]{2}{*}{ Pct } & \multicolumn{3}{|c|}{5 Million } & \multicolumn{3}{|c|}{250 Million } & \multicolumn{3}{|c|}{1 Billion } \\
\hline & Act & Sim & $\%<$ Act & Act & Sim & $<<A c t$ & Act & Sim & $\%<$ Act \\
\hline \multicolumn{4}{|c|}{$\begin{array}{lrrr}\text { 3F-CAPM, } & \text { et Returns } \\
1 & -3.89 & -2.33 & 0.01 \\
2 & -3.47 & -2.05 & 0.01 \\
3 & -3.19 & -1.87 & 0.01 \\
4 & -2.99 & -1.74 & 0.01 \\
5 & -2.85 & -1.64 & 0.01 \\
10 & -2.38 & -1.27 & 0.01 \\
20 & -1.77 & -0.83 & 0.00 \\
30 & -1.32 & -0.52 & 0.02 \\
40 & -0.96 & -0.25 & 0.02 \\
50 & -0.68 & 0.00 & 0.02 \\
60 & -0.32 & 0.26 & 0.07 \\
70 & 0.05 & 0.53 & 0.37 \\
80 & 0.45 & 0.85 & 2.08 \\
90 & 1.00 & 1.29 & 39.35 \\
95 & 1.52 & 1.65 & 33.11 \\
96 & 1.66 & 1.76 & 38.83 \\
97 & 1.86 & 1.89 & 48.72 \\
98 & 2.11 & 2.07 & 59.76 \\
99 & 2.37 & 2.36 & 56.75\end{array}$} & $\begin{array}{l}-3.85 \\
-3.45 \\
-3.11 \\
-2.94 \\
-2.77 \\
-2.25 \\
-1.61 \\
-1.18 \\
-0.81 \\
-0.56 \\
-0.26 \\
0.07 \\
0.44 \\
0.94 \\
1.38 \\
1.45 \\
1.65 \\
1.90 \\
2.19\end{array}$ & $\begin{array}{l}-2.32 \\
-2.04 \\
-1.86 \\
-1.73 \\
-1.63 \\
-1.27 \\
-0.83 \\
-0.52 \\
-0.25 \\
0.00 \\
0.25 \\
0.52 \\
0.84 \\
1.28 \\
1.64 \\
1.75 \\
1.89 \\
2.06 \\
2.35\end{array}$ & $\begin{array}{l}0.05 \\
0.03 \\
0.06 \\
0.05 \\
0.05 \\
0.10 \\
0.13 \\
0.18 \\
0.24 \\
0.18 \\
0.31 \\
0.87 \\
2.39 \\
7.33 \\
16.66 \\
13.25 \\
21.67 \\
32.46 \\
34.60\end{array}$ & $\begin{array}{l}-3.46 \\
-3.23 \\
-2.94 \\
-2.82 \\
-2.62 \\
-2.23 \\
-1.61 \\
-1.07 \\
-0.73 \\
-0.43 \\
-0.14 \\
0.17 \\
0.48 \\
1.02 \\
1.51 \\
1.66 \\
1.78 \\
2.13 \\
2.30\end{array}$ & $\begin{array}{r}-2.33 \\
-2.04 \\
-1.87 \\
-1.73 \\
-1.63 \\
-1.27 \\
-0.83 \\
-0.52 \\
-0.25 \\
-0.00 \\
0.25 \\
0.51 \\
0.83 \\
1.27 \\
1.64 \\
1.75 \\
1.88 \\
2.07 \\
2.36\end{array}$ & $\begin{array}{l}0.67 \\
0.28 \\
0.37 \\
0.29 \\
0.34 \\
0.17 \\
0.19 \\
0.85 \\
1.30 \\
1.92 \\
3.04 \\
4.74 \\
5.74 \\
16.87 \\
35.80 \\
42.47 \\
41.50 \\
62.44 \\
48.89\end{array}$ \\
\hline \multicolumn{10}{|c|}{ 3F-CAPM, Gross Returns } \\
\hline $\begin{array}{l}1 \\
2 \\
3 \\
4 \\
5 \\
10 \\
20 \\
30 \\
40 \\
50 \\
60 \\
70 \\
80 \\
90 \\
95 \\
96 \\
97 \\
98 \\
99\end{array}$ & $\begin{array}{r}-3.16 \\
-2.70 \\
-2.45 \\
-2.28 \\
-2.16 \\
-1.71 \\
-1.14 \\
-0.69 \\
-0.38 \\
-0.03 \\
0.31 \\
0.64 \\
1.04 \\
1.59 \\
2.03 \\
2.19 \\
2.35 \\
2.57 \\
2.94\end{array}$ & $\begin{array}{r}-2.33 \\
-2.05 \\
-1.88 \\
-1.75 \\
-1.64 \\
-1.28 \\
-0.84 \\
-0.52 \\
-0.25 \\
0.00 \\
0.25 \\
0.52 \\
0.84 \\
1.29 \\
1.65 \\
1.76 \\
1.89 \\
2.07 \\
2.36\end{array}$ & $\begin{array}{r}1.08 \\
2.06 \\
2.78 \\
3.21 \\
3.18 \\
4.25 \\
8.39 \\
20.47 \\
26.22 \\
43.44 \\
63.07 \\
72.42 \\
83.25 \\
89.56 \\
91.58 \\
93.25 \\
93.79 \\
94.24 \\
95.64\end{array}$ & $\begin{array}{r}-2.94 \\
-2.58 \\
-2.35 \\
-2.16 \\
-2.07 \\
-1.57 \\
-1.02 \\
-0.60 \\
-0.29 \\
0.02 \\
0.30 \\
0.61 \\
0.96 \\
1.49 \\
1.90 \\
2.05 \\
2.19 \\
2.45 \\
2.80\end{array}$ & $\begin{array}{r}-2.32 \\
-2.04 \\
-1.86 \\
-1.73 \\
-1.63 \\
-1.26 \\
-0.83 \\
-0.52 \\
-0.25 \\
0.00 \\
0.25 \\
0.52 \\
0.84 \\
1.28 \\
1.65 \\
1.76 \\
1.89 \\
2.07 \\
2.35\end{array}$ & $\begin{array}{r}4.23 \\
4.89 \\
5.70 \\
7.05 \\
6.03 \\
10.75 \\
19.21 \\
33.11 \\
41.00 \\
53.18 \\
59.72 \\
67.02 \\
72.97 \\
81.56 \\
83.03 \\
85.29 \\
85.11 \\
88.72 \\
89.83\end{array}$ & $\begin{array}{r}-2.77 \\
-2.41 \\
-2.21 \\
-2.03 \\
-1.96 \\
-1.61 \\
-1.03 \\
-0.58 \\
-0.18 \\
0.07 \\
0.39 \\
0.66 \\
1.00 \\
1.49 \\
1.98 \\
2.10 \\
2.31 \\
2.41 \\
2.69\end{array}$ & $\begin{array}{r}-2.33 \\
-2.04 \\
-1.87 \\
-1.73 \\
-1.63 \\
-1.27 \\
-0.83 \\
-0.52 \\
-0.25 \\
-0.00 \\
0.25 \\
0.51 \\
0.83 \\
1.27 \\
1.64 \\
1.74 \\
1.88 \\
2.06 \\
2.36\end{array}$ & $\begin{array}{l}11.51 \\
13.17 \\
13.37 \\
15.34 \\
12.89 \\
9.83 \\
18.83 \\
37.29 \\
64.30 \\
64.49 \\
77.20 \\
77.10 \\
78.76 \\
81.30 \\
87.81 \\
88.05 \\
90.55 \\
84.98 \\
82.01\end{array}$ \\
\hline
\end{tabular}




\section{References}

Barras, Laurent, Olivier Scaillet and Russ Wermers (2010), 'False discoveries in mutual fund performance: Measuring luck in estimated alphas', The Journal of Finance 65(1), 179-216.

Berk, Jonathan B and Richard C Green (2004), 'Mutual fund flows and performance in rational markets', Journal of Political Economy 112(6), 1269-1295.

Carhart, Mark M (1997), 'On persistence in mutual fund performance', The Journal of Finance 52(1), 5782.

Center for Research in Security Prices (2014), 'Survivor-bias-free US mutual fund guide'.

URL: http://www.crsp.com/files/MF_Sift_Guide.pdf

Cuthbertson, Keith, Dirk Nitzsche and Niall O'Sullivan (2008), 'UK mutual fund performance: Skill or luck?', Journal of Empirical Finance 15(4), 613-634.

Evans, Richard B (2010), 'Mutual fund incubation', The Journal of Finance 65(4), 1581-1611.

Fama, Eugene F and Kenneth R French (1993), 'Common risk factors in the returns on stocks and bonds', Journal of Financial Economics 33(1), 3-56.

Fama, Eugene F and Kenneth R French (2010), 'Luck versus skill in the cross-section of mutual fund returns', Journal of Finance 65(5), 1915-1947.

Fama, Eugene, F and Kenneth R French (2015), 'A five-factor asset pricing model', Journal of Financial Economics 116(1), 1-22.

Ferson, Wayne E and Rudi W Schadt (1996), 'Measuring fund strategy and performance in changing economic conditions', The Journal of Finance 51(2), 425-461.

French, Kenneth R (2008), 'Presidential address: The cost of active investing', The Journal of Finance 63(4), 1537-1573.

Huang, Rong, Keith Pilbeam and William Pouliot (2019), 'Do actively managed U.S. mutual funds produce positive alpha?', Journal of Economic Behavior and Organisation (DOI:10.1016/j.jebo.2019.03.006).

Investment-Company-Institute (2018), Fact Book, 58 edn, Investment Company Institute.

Investment-Company-Institute (2019), 'Fact book'.

URL: https://www.icifactbook.org/

Jaing, Hao and Verardo Verardo (2018), 'Does herding behavior reveal skill? an analysis of mutual fund performance', Journal of Finance (2), 2229-2269.

Kacperczyk, Marcin, Clemens Sialm and Lu Zheng (2008), 'Unobserved actions of mutual funds', Review of Financial Studies 21(6), 2379-2416.

Kosowski, Robert, Allan Timmermann, Russ Wermers and Hal White (2006), 'Can mutual fund "stars" really pick stocks? New evidence from a bootstrap analysis', The Journal of Finance 61(6), 2551-2595.

Tirole, Jean (2006), The Theory of Corporate Finance, Princeton University Press. 